\title{
Spectroscopic Enlightening of the Local Structure of VOx Active Sites in Catalysts for the ODH of Propane
}

\begin{tabular}{|r|l|}
\hline Journal: & The Journal of Physical Chemistry \\
\hline Manuscript ID: & jp-2012-07031b.R1 \\
\hline Manuscript Type: & Article \\
\hline Date Submitted by the Author: & n/a \\
\hline Complete List of Authors: & $\begin{array}{l}\text { Rossetti, Ilenia; Università degli Studi di Milano, Dip. Chimica fisica ed } \\
\text { Elettrochimica } \\
\text { Mancini, Giulia; Università degli Studi di Pavia, Chimica } \\
\text { Ghigna, Paolo; Università di Pavia, Dipartimento di Chimica Fisica } \\
\text { Scavini, Marco; University of Milan, Chimica Fisica ed Elettrochimica } \\
\text { Piumetti, Marco; Politecnico di Torino, Applied Science and Technology } \\
\text { Bonelli, Barbara; Politecnico di Torino, Materials Science \& Chemical } \\
\text { Engineering } \\
\text { Cavani, Fabrizio; University of Bologna, Dip Chimica Indust Materiali } \\
\text { Comite, Antonio; Università degli Studi di Genova, Chimica e Chimica } \\
\text { Industriale }\end{array}$ \\
\hline \hline
\end{tabular}




\title{
SPECTROSCOPIC ENLIGHTENING OF THE LOCAL STRUCTURE OF VO $\mathrm{x}_{\mathrm{x}}$ ACTIVE SITES IN CATALYSTS FOR THE ODH OF PROPANE
}

\author{
Ilenia Rossetti ${ }^{\mathrm{a}^{*}}$, Giulia Fulvia Mancini ${ }^{\mathrm{b}^{* \star}}$, Paolo Ghigna ${ }^{\mathrm{b}}$, Marco Scavini ${ }^{\mathrm{a}}$, Marco Piumetti ${ }^{\mathrm{c}}$, \\ Barbara Bonellic ${ }^{\mathrm{c}}$ Fabrizio Cavani ${ }^{\mathrm{d}}$, Antonio Comite ${ }^{\mathrm{e}}$
}

a Dip. Chimica, Università degli Studi di Milano, CNR-ISTM and INSTM Unit MilanoUniversità, v. C. Golgi 19, 20133 Milano, Italy

${ }^{b}$ Dip. Chimica, Università degli Studi di Pavia Unità and INSTM Unit Pavia, V.le Taramelli 13, I-27100, Pavia, Italy

${ }^{\mathrm{c}}$ Dip. Scienza Applicata e Tecnologia, Politecnico di Torino and INSTM unit of TorinoPolitecnico, Corso Duca degli Abruzzi 24, I-10129 Turin, Italy.

${ }^{d}$ Dip. Chimica Industriale e dei Materiali, Viale Risorgimento 4, 40136 Bologna, Italy

e Dip. Chimica e Chimica Industriale, Università degli Studi di Genova, via Dodecaneso 31, 16146 Genova, Italy

\footnotetext{
* Corresponding author: fax +39-02-50314300; e-mail ilenia.rossetti@ unimi.it.

${ }^{* *}$ Present address: Lab. for Ultrafast Microscopy and Electron Scattering, Faculty of Basic Sciences, ICMP

École Polytechnique Fédérale de Lausanne (EPFL), EPFL campus, CHH2 545, Station 6, CH-1015 Lausanne, CH 


\begin{abstract}
Site isolation of $\mathrm{V}$ active sites has been often correlated to catalytic performance for the oxidative dehydrogenation $(\mathrm{ODH})$ of propane to propylene. In particular, catalyst selectivity seems favoured by high $\mathrm{V}$ dispersion. The latter property is hardly attainable by traditional preparation methods, especially by impregnation except at very low $\mathrm{V}$ loading, which however may lead to a too high surface exposure of the acidic sites of the support. In this paper, the effect of the preparation procedure on catalyst properties has been investigated, particularly considering catalysts prepared by flame pyrolysis, a synthesis method which induced a very high $\mathrm{V}$ dispersion also at relatively high vanadium loading. Transmission electron microscopy also allowed us to assess $\mathrm{V}$ oxide dispersion depending on both the support type and the preparation method. Furthermore, the local structure of the $\mathrm{V}$ active sites has been deeply investigated by X-ray Absorption Spectroscopy, allowing us to propose a possible structure of the active sites.

The average oxidation state of surface $\mathrm{V}$ species was then studied by X-ray Photoelectron Spectroscopy (XPS), showing a role of $\mathrm{V}$ oxidation state on catalyst selectivity. The catalytic performance has been interpreted on the basis of $\mathrm{V}$ species and catalyst acidity (as measured by IR spectroscopy), another fundamental parameter that in turn results to be correlated with $\mathrm{V}$ dispersion on different supports. More selective catalysts were indeed characterized by the presence of weaker Brønsted acidic sites.
\end{abstract}

Keywords: Oxidative dehydrogenation $(\mathrm{ODH})$ of propane; Propylene production; V-based catalysts; X-ray absorption. 


\section{1 - Introduction}

Light olefins are important building blocks for polymers and intermediates industry ${ }^{1}$. The need for light olefins is progressively growing, with a higher rate for propene, leading to the necessity of alternative production routes ${ }^{2}$. Direct dehydrogenation can be an interesting alternative when low value feedstock is available. However, it is an endothermal reaction needing a high energy input, it is equilibrium controlled and the catalyst may be easily deactivated by coking. The oxidative dehydrogenation $(\mathrm{ODH})$ of light paraffins to the corresponding olefins has been proposed as a means to overcome all these limitations. In addition, oxygen limits severe catalyst coking ${ }^{3}$. In spite of the considerable attention paid to this process and testified by a certain number of patents (see e.g. ${ }^{4,5}$ and references therein), the $\mathrm{ODH}$ technology can be hardly considered mature and it has not yet reached industrial application due to selectivity issues. Indeed, oxygen should ideally consume $\mathrm{H}_{2}$, but paraffins and (most of all) olefins combustion is an unavoidable side reaction, which drives products yield below acceptable limits.

Among the possible catalyst formulations, V-based catalysts proved active and selective for the ODH of propane ${ }^{2}$. Different possible reaction pathways have been proposed ${ }^{6,7}$, depending on the polymerisation degree of $\mathrm{V}$ species on the surface.

According to DFT calculations, a one-electron reduction seems more likely for isolated $\mathrm{V}^{5+}$ species, leading to $\mathrm{V}^{4+}$, which is readily reoxidised by $\mathrm{O}_{2}$. A two-electron reduction mechanism is also proposed for dimeric $\mathrm{V}$ species ${ }^{7}$ and it is not excluded also for the monomeric ones ${ }^{6}$ and it is assumed as the preferred reaction pathway by some authors ${ }^{8}$. A strong dependence on the support has been evidenced, the $\mathrm{V}^{4+} / \mathrm{V}^{3+}$ ratio in the reduced catalyst depending on the possible delocalisation of unpaired electrons and on the amount of oxygen vacancies of the support (especially for $\left.\mathrm{TiO}_{2}\right)^{9}$, though discrepancies are found in the literature on this point. Indeed, according to Koranne et al. ${ }^{10}$ a preferential $\mathrm{V}^{5+} \rightarrow \mathrm{V}^{4+}$ 
reduction would occur when using $\mathrm{Al}_{2} \mathrm{O}_{3}$ as support, while a $70 \% \mathrm{~V}^{5+} \rightarrow \mathrm{V}^{3+}$ reduction has been predicted for silica supported samples. By contrast, other researchers ${ }^{11,12}$ report that the latter reduction path holds for $\mathrm{VO}_{\mathrm{x}} / \mathrm{TiO}_{2}$ catalysts, whereas that leading to $\mathrm{V}^{4+}$ is active for $\mathrm{Al}_{2} \mathrm{O}_{3}$ and $\mathrm{SiO}_{2}$ based samples. Furthermore, the vanadyl oxygen does not seem responsible for the first oxidative formation of propene, but it is likely involved in its nonselective complete oxidation ${ }^{13}$. This may explain the reason why stronger $\mathrm{V}=\mathrm{O}$ bonds observed for some V-Si-O systems with respect to $\mathrm{V}$-Al-O ones were correlated to a higher selectivity to propene ${ }^{14-16}$.

A detailed assessment of the nature of V-containing species can be done by coupling several characterisation techniques, among which Raman, FT-IR, UV-Vis spectroscopies, X-ray Diffraction (XRD) and Temperature Programmed Reduction (TPR), the latter technique assessing a mean oxidation state of $\mathrm{V}^{\mathrm{n}+}$ species. Four types of $\mathrm{V}$-containing species have been identified in supported $\mathrm{VO}_{\mathrm{x}}$ catalysts: (1) isolated surface $\mathrm{VO}_{4}$ species containing one terminal $\mathrm{V}=\mathrm{O}$ bond and three bridging $\mathrm{V}$-O-support bonds, (2) polymeric surface $\mathrm{VO}_{4}$ species containing one terminal $\mathrm{V}=\mathrm{O}$ bond and three bridging $\mathrm{V}-\mathrm{O}-\mathrm{V} / \mathrm{V}-\mathrm{O}$ support bonds, (3) crystalline $\mathrm{V}_{2} \mathrm{O}_{5}$ and (4) compounds forming mixed oxides with the support, usually upon calcination at high temperatures (e.g. $\mathrm{Zr}\left(\mathrm{V}_{2} \mathrm{O}_{7}\right)_{2}, \mathrm{AlVO}_{4}, \mathrm{~V}_{x} \mathrm{Ti}_{1-x} \mathrm{O}_{2}$, $\left.\mathrm{NbVO}_{5}, \mathrm{Mg}_{3}\left(\mathrm{VO}_{4}\right)_{2}, \mathrm{Mg}_{2} \mathrm{~V}_{2} \mathrm{O}_{7}\right)^{8,17}$.

At low $\mathrm{V}$ loading, isolated monovanadate species are usually present, which progressively oligomerise and polymerise up to a monolayer with increasing $\mathrm{V}$ concentration; beyond this point $\mathrm{V}_{2} \mathrm{O}_{5}$ segregation occurs. Different $\mathrm{V}$ loadings and $\mathrm{V}$ surface densities corresponding to monolayer completion characterise each support ${ }^{8,18-20}$. For example, the extent of polymerisation follows the trend $\mathrm{Al}_{2} \mathrm{O}_{3}>\mathrm{ZrO}_{2} \gg \mathrm{SiO}_{2}{ }^{8}$. Isolated $\mathrm{VO}_{\mathrm{x}}$ species can be found on $\mathrm{SiO}_{2}$ up to ca. $2 \mathrm{~V} / \mathrm{nm}^{2}$ surface density, whereas alumina- or titania-supported samples showed higher surface density $\left(7-8 \mathrm{~V} / \mathrm{nm}^{2}\right)$, corresponding to polymeric vanadyl species. With the latter supports, it was difficult to attain high $\mathrm{V}$ dispersion, unless by 
excessively decreasing the $\mathrm{V}$ loading, with detrimental effects on both activity and selectivity ${ }^{8}$.

High reaction rates for the $\mathrm{ODH}$ of $\mathrm{C}_{2}-\mathrm{C}_{4}$ paraffins are found with polymerised vanadate species, up to the formation of a $\mathrm{VO}_{x}$ monolayer, while lower activity and selectivity are usually associated with the presence of bulk $\mathrm{V}_{2} \mathrm{O}_{5}{ }^{21-23}$. Furthermore, when the support has a strong Lewis acidity ${ }^{24}$ the formation of a compact $\mathrm{VO}_{\mathrm{x}}$ monolayer completely covering the support acid sites is desired to improve selectivity.

To sum up, a deepening of the correlation between $\mathrm{V}$-site properties and catalyst selectivity would be welcome. Indeed, attempts to increase $\mathrm{V}$ dispersion by common preparation procedures often ended in the enhancement of different factors such as acidity, support exposure and activity, etc.

A detailed assessment of $\mathrm{V}$ local structure may help in elucidating activity and selectivity issues, above all if coupled with a detailed investigation on catalyst acidity. Therefore, the present investigation aims at defining the active site structure of $\mathrm{VO}_{\mathrm{x}} / \mathrm{SiO}_{2}$ and $\mathrm{VO}_{\mathrm{x}} / \mathrm{Al}_{2} \mathrm{O}_{3}$ catalysts characterised by variable metal loading and prepared by different techniques. XRay Absorption Spectroscopy (XAS) has been used to assess the local environment of the active metal and the results, compared with X-ray diffraction, Micro-Raman, Fourier Transform Infra-Red (FT-IR) spectroscopies and Electron Paramagnetic Resonance (EPR) data, helped in interpreting the catalytic performance. Transmission Electron Microscopy (TEM) allowed assessing $\mathrm{V}$ dispersion and location on the support surface. $\mathrm{A}$ tentative structure of the active sites is also proposed. Finally, a correlation between $\mathrm{V}$ dispersion, oxidation state and acidity on different supports has been also introduced.

\section{2 - Experimental}

\section{1 - Sample Preparation}


A detailed description of the flame pyrolysis (FP) preparation procedure and of the effect of the main operating parameters on catalyst properties can be found elsewhere ${ }^{25-28}$. A 0.1$0.2 \mathrm{M}$ solution of precursors (with respect to the nominal oxide composition) in organic solvent was fed to FP the burner $\left(4.4 \mathrm{~cm}^{3} / \mathrm{min}\right)$, together with $5 \mathrm{~L} / \mathrm{min}$ of oxygen (SIAD, purity $>99.95 \%$ ). The cross section area of the burner was adjusted so to have a pressure drop of 0.4 bar across the nozzle. The catalyst powder so produced was collected by means of a $10 \mathrm{kV}$ electrostatic precipitator ${ }^{25,29}$.

$\mathrm{Al}\left(\mathrm{NO}_{3}\right)_{3}{ }^{*} 9 \mathrm{H}_{2} \mathrm{O}$, tetra-ethyl-orthosilicate (TEOS) and $\mathrm{V}$ oxi-acetyl-acetonate were used as precursors ${ }^{14-16}$. The solvent was a 1:1 ( $\left.\mathrm{vol} / \mathrm{vol}\right)$ mixture of ethanol and 1-octanol for the alumina based samples and 1:1 (vol/vol) mixture of ethanol and propionic acid for the silica based ones.

Comparative samples have been prepared by impregnation of $\mathrm{FP}$-prepared $\mathrm{SiO}_{2}$ and $\mathrm{Al}_{2} \mathrm{O}_{3}$ supports from a $\mathrm{NH}_{4} \mathrm{VO}_{3}$ solution (samples $\mathrm{V} 10 \mathrm{Si}-\mathrm{i}$ and $\mathrm{V} 10 \mathrm{Al}-\mathrm{i}$ ). The catalysts were then dried and calcined at $700^{\circ} \mathrm{C}$ in air flow.

A different preparation route has also been used, namely co-gel formation from TEOS and ammonium vanadate ${ }^{30}$, achieving a $\mathrm{V}_{2} \mathrm{O}_{5}$ content of 6.7 wt\% (sample VAG1) and 15 wt $\%$ (sample VAG3).

Samples composition is reported in Table 1, where silica and alumina supported catalysts are represented by $\mathrm{Si}$ and $\mathrm{Al}$ in the sample code, respectively.

\section{2 - Samples Characterisation}

Specific surface area (BET) was determined by $\mathrm{N}_{2}$ adsorption/desorption at $-196^{\circ} \mathrm{C}$ on a Micromeritics ASAP2010 instrument, after outgassing overnight at $300^{\circ} \mathrm{C}$ (Table 1). XRD analysis was carried out on a Philips PW3020 powder diffractometer, by using the Nifiltered $\mathrm{Cu}$ K $\alpha$ radiation $(\lambda=1.5418 \AA$ ). The diffractograms obtained were compared with literature data for phase recognition ${ }^{31}$. 
X-ray absorption spectra were collected at the GILDA beamline in the ESRF facility (Grenoble, France). Ca. $50 \mathrm{mg}$ of sample were carefully grinded and mixed with cellulose powder, then pressed to obtain a thin wafer. Samples of $\mathrm{V}_{2} \mathrm{O}_{5}$ and $\mathrm{AlVO}_{4}$ were used as reference. The spectra have been collected in transmission mode, using ion chambers as detectors and a Si(311) double crystal monochromator. The energy calibration has been made by measuring the spectrum of a reference $V$ foil, simultaneously with the sample by using a third ion chamber. The EXAFS data analysis has been made by means of the iXAFS package ${ }^{32,33}$. For the XANES analysis, the spectra have been pre-edge fitted by a straight line, and normalised to unit edge jump.

Scanning Electron Microscopy (SEM) observations have been carried out using a Leo Stereoscan 440 microscope equipped with an EDX probe (Oxford Link System, Ge detector) and with a back scattering detector (Centaurus). The catalyst powder has been carefully distributed on the analysis stub and sputtered with carbon in order to observe its morphology and to perform element analysis.

Trasmission Electron Microscopy (TEM) investigations have been carried out using a JEOL JEM 2010 equipped with an EDX analysis probe (Oxford Link System, Si(Li) detector). The catalysts samples have been carefully dispersed in isopropanol using a ultrasound bath to break-up the aggregates and then a sample drop has been deposited on a Lacey carbon grid.

XPS (X-ray photoelectron spectroscopy) spectra were recorded on a PHI 5000 Versa Probe apparatus using a band-pass energy of $187.85 \mathrm{eV}, 45^{\circ}$ take off angle and a $100.0 \mu \mathrm{m}$ diameter X-ray spot size. Curve-fits were performed by means of Multipak 9.0 software, after Shirley background subtraction.

IR spectra were collected on a FT-IR spectrophotometer (Equinox 55, Bruker), equipped with a MCT (Mercury Cadmium Telluride) cryodetector. For IR measurements, powder samples were pressed into thin self-supporting wafers (density of about $10 \mathrm{mg} \mathrm{cm}$ - 
${ }^{2}$ ) and outgassed at $150^{\circ} \mathrm{C}$ in a standard vacuum frame (residual pressure below $10^{-3}$ mbar) by using IR cells equipped with $\mathrm{KBr}$ windows. The outgassing temperature was chosen in order to preserve Brønsted acidic sites that are removed at higher outgassing temperatures ${ }^{14}$. $\mathrm{NH}_{3}$ adsorption was run at room temperature on samples outgassed at $150^{\circ} \mathrm{C}$ by dosing increasing amounts of ammonia (partial pressure in the $0.00-30.0$ mbar range) and evacuating to remove the reversible fraction of the adsorbate.

\section{3 - Catalytic activity tests}

Catalytic activity was measured by means of a continuous, quartz tubular reactor (i.d.= 7 $\mathrm{mm})$ heated by a furnace. The catalyst $(0.90 \mathrm{~mL}, 0.5-0.6 \mathrm{~g}, 0.425$-to- $0.600 \mathrm{~mm}$ particle size) was activated prior to each run in $20 \mathrm{~cm}^{3} / \mathrm{min}$ flowing air, while increasing temperature by $10^{\circ} \mathrm{C} / \mathrm{min}$ up to $550^{\circ} \mathrm{C}$, then kept for $1 \mathrm{~h}$. Every sample was tested under aerobic (co-feed) or anaerobic conditions. In the former case, the flow rates of the reactants were $11 \mathrm{~cm}^{3} / \mathrm{min}$ of $\mathrm{C}_{3} \mathrm{H}_{8}(20 \mathrm{~mol} \%)+11 \mathrm{~cm}^{3} / \mathrm{min}$ of $\mathrm{O}_{2}(20 \mathrm{~mol} \%)+28 \mathrm{~cm}^{3} / \mathrm{min}$ of $\mathrm{He}+4 \mathrm{~cm}^{3} / \mathrm{min}$ of $\mathrm{N}_{2}$ (60 mol\% inert). For the "anaerobic mode" flow rates were 6 $\mathrm{cm}^{3} / \mathrm{min}$ of $\mathrm{C}_{3} \mathrm{H}_{8}(22 \mathrm{~mol} \%)+19 \mathrm{~cm}^{3} / \mathrm{min}$ of $\mathrm{He}+2 \mathrm{~cm}^{3} / \mathrm{min}$ of $\mathrm{N}_{2}$. The contact time was 1 $\mathrm{s}$ for the former and $2 \mathrm{~s}$ for the latter testing mode, respectively, in both cases operating as an integral reactor. The outflowing gas was analysed by means of a micro-GC (Agilent 3000A), equipped with a TCD detector, Plot-Q, OV-1 and MS-5A columns for a complete detection of the effluent products. In addition to propane, propylene, $\mathrm{CO}$ and $\mathrm{CO}_{2}$, products quantification included $\mathrm{H}_{2}$, light alkanes and alkenes, acetic and acrylic acids.

The catalyst was diluted with inert steatite particles and bed temperature was measured by means of an axial thermocouple $\left(\Delta \mathrm{T}_{\max }=7^{\circ} \mathrm{C}\right.$ in co-feed mode, $\Delta \mathrm{T}_{\max }=5^{\circ} \mathrm{C}$ during testing under anaerobic conditions and subsequent re-oxidation). Mass transfer was not limiting the kinetics of the reaction, as assessed during the determination of the reaction rates at 
different temperature under aerobic conditions (at low propane conversion). The activation energy resulted around $120 \mathrm{~kJ} / \mathrm{mol}$ for $\mathrm{V} / \mathrm{Al}$ samples ${ }^{15}$.

\section{3 - Results and discussion}

\subsection{Survey of previous results}

As for the FP-prepared samples, the XRD patterns of silica supported samples were always amorphous (Table 1 ). $\mathrm{V}_{2} \mathrm{O}_{5}$ reflections appeared only at high $\mathrm{V}$ loading (> $28 \mathrm{wt} \%$ ) ${ }^{14,16}$. On the contrary, either $\delta$ - or $\eta-\mathrm{Al}_{2} \mathrm{O}_{3}$ was detected in the alumina supported samples, in which the occurrence of $\mathrm{V}_{2} \mathrm{O}_{5}$ was always observed even at the lowest $\mathrm{V}$ loading ${ }^{15,16}$. These results were also confirmed by Micro-Raman spectroscopy ${ }^{14}$, which evidenced the absence of $\mathrm{V}_{2} \mathrm{O}_{5}$ in $\mathrm{V} 10 \mathrm{Si}$ sample, the spectrum of which was only characterised by two weak bands at 1027 and $512 \mathrm{~cm}^{-1}$, ascribable to isolated $\mathrm{V}=\mathrm{O}$ species ${ }^{34}$. In the case of Alsupported samples ${ }^{15}$, Raman spectra always evidenced the presence of $\mathrm{V}_{2} \mathrm{O}_{5}$, its content increasing with $\mathrm{V}$ loading. However, with V10Al sample also bands attributed to $\mathrm{VO}_{\mathrm{x}}$ and isolated $\mathrm{V}=\mathrm{O}$ species were detected. The latter were absent with sample $\mathrm{V} 10 \mathrm{Al}-\mathrm{i}$, prepared by impregnation, which resulted to be much more similar to sample V50Al.

Finally, electron paramagnetic resonance evidenced ferromagnetic domains constituted by agglomerated V(IV) sites in V10Al-i and V10Si-i samples prepared by impregnation and absent in the corresponding FP ones, further confirming the higher $\mathrm{V}$ dispersion in the latter catalysts ${ }^{14-16}$.

All these evidences induced the conclusion of a much higher $\mathrm{V}$ dispersion of the FPprepared samples, of course decreasing with raising $\mathrm{V}$ loading, with respect to those prepared by impregnation, at similar $\mathrm{V}$ concentration. This reflected on catalyst performance ${ }^{14-16}$, showing a higher selectivity (at isoconversion) for sample V10Si with 
respect to its homologue prepared by impregnation (V10Si-i), especially when operating under anaerobic conditions. Similar conclusions, though less evident, may be drawn for sample V10Al when compared with V10Al-i.

This intriguing statement has been here verified by comparing some FP-prepared samples with similar ones prepared by co-gelation, a method which should also lead to high $\mathrm{V}$ dispersion, and with other samples prepared by $\mathrm{V}$ impregnation of FP-prepared supports.

\section{2 - SEM-TEM analysis}

SEM pictures evidenced more uniform and smaller particles for $\mathrm{SiO}_{2}$ than for $\mathrm{Al}_{2} \mathrm{O}_{3}$ samples prepared by FP (Fig. 1). This is connected to the precursors solubility and to the preparation procedure. Propionic acid was used for the preparation by FP of the silica based samples, whereas alcohols were necessary to dissolve the alumina precursor, as detailed in the Experimental section. As already reported elsewhere ${ }^{27,28}$, ethanol, and in general alcohols, is not the best choice for this synthetic procedure due to too high volatility, though sometimes forced by solubility issues. Too fast solvent evaporation may indeed lead to uneven particle size distribution.

EDX analysis confirmed a rather uniform $\mathrm{V}$ distribution in every sample, notwithstanding a better homogeneity for the silica based samples, with respect to alumina supported ones. Selected TEM pictures are reported in Fig. 2: sample V10Si showed a rather amorphous appearance, in accordance with XRD, without any evidence of phase segregation. At increasing $\mathrm{V}$ loading, $\mathrm{V}_{2} \mathrm{O}_{5}$ aggregates became evident (Fig. $2 b-d$ ), with a characteristic rod like shape and well defined crystal planes separation. A similar picture was obtained with sample $\mathrm{V} 50 \mathrm{Al}$, though $\mathrm{V}_{2} \mathrm{O}_{5}$ rods resulted to be much more interacting with the support, since they were grown on it (Fig. 2e). Such results were confirmed by TEM-EDX 
maps (Fig. 3). In particular, V was homogeneously dispersed in sample V10Si (Fig. 3a), whereas aggregates were visible on the shell of V10Al particles (Fig. 3b).

Electron microscopy data thus show a different $\mathrm{V}$ distribution depending on its loading and on the support. A higher surface interaction between $\mathrm{V}$ and $\mathrm{Al}$ appears, accompanied by a lower dispersion degree.

\section{3 - XPS analysis}

Fig. 4 reports XPS spectra in the $O$ 1s (a) and $V 2 p$ BE regions (b). The $O$ 1s spectra reported in Fig. 4a present different features, depending on both $\mathrm{V}$ loading and support type. According to literature, the $\mathrm{O} 1 \mathrm{~s}$ peak is seen at $533 \pm 0.5 \mathrm{eV}$ in silica and at $530 \pm$ $0.5 \mathrm{eV}$ in $\mathrm{V}_{2} \mathrm{O}_{5}{ }^{35}$ : with V28Si sample, the main peak is seen at $533.1 \mathrm{eV}$, indicating the presence of oxygen atoms bonded to silicon atoms ${ }^{35}$. With the same sample, a minor component at lower $\mathrm{BE}$ values is also observed, assigned to $\mathrm{O}$ atoms interacting with vanadium. The latter assignment is confirmed by the fact that at higher $\mathrm{V}$ loading (V50Si sample) the main peek is seen at $530.5 \mathrm{eV}$, a $\mathrm{BE}$ value corresponding to surface $\mathrm{V}_{2} \mathrm{O}_{5}$, in agreement with previous Raman studies ${ }^{14}$. With the impregnated sample (V10Si-i), a (minor) component at $530.5 \mathrm{eV}$ is also observed, its lower intensity being due to the smaller vanadium content, along with a main band peaking at $532.7 \mathrm{eV}$, due to oxygen atoms related to $\mathrm{Si}$. With $\mathrm{V} 10 \mathrm{Si}$, the peak of oxygen has a maximum at $532.5 \mathrm{eV}$, that is intermediate between literature $\mathrm{BE}$ values of oxygen in silica $(533 \mathrm{eV})$ and $\mathrm{V}_{2} \mathrm{O}_{5}(530 \mathrm{eV})$, thus confirming the better vanadium dispersion in the latter sample.

Interpretation of XPS of $\mathrm{Al}_{2} \mathrm{O}_{3}$-supported samples may be complicated by the fact that the O1s peak is at $531 \pm 0.5 \mathrm{eV}$ in $\mathrm{Al}-\mathrm{O}$ bonds and at $533 \pm 0.5 \mathrm{eV}$ for $\mathrm{Al}-\mathrm{OH}$ groups ${ }^{36}$, so it is hardly distinguishable from of oxygen in vanadia. Features of the O1s XP spectra of both V10Al and V10Al-i are similar to that of V50Si, indicating the presence of oxygen atoms 
ascribed to a separate $\mathrm{V}_{2} \mathrm{O}_{5}$ phase, along with some oxygen atoms related to $\mathrm{Al}$, confirming that it was not possible to reach a good dispersion of vanadium on $\mathrm{Al}_{2} \mathrm{O}_{3}$, even at a low $\mathrm{V}$ loading. This is probably due to the nature of the alumina matrix, that is less "pliable" with respect to silica and it is not able to accommodate vanadium atoms with a high dispersion. The high pliability of the Si-O-Si bond is well known and it is responsible, for instance, of the variety of silica polymorphs, i.e. amorphous or in several crystalline phases ${ }^{37}$. Fig. $4 b$ reports the corresponding XP spectra in the V2p BE region: at higher $B E$, the features of $V 2 p 1 / 2$ are observed and will not be addressed further, so the focus will be on the main peak due to the $\mathrm{V} 2 \mathrm{p} 3 / 2$ transition. The sample $\mathrm{V} 10 \mathrm{Si}$ shows a signal at higher BE values with respect to the other samples, that is assigned to the presence of hydrated $\mathrm{V}^{5+}$ species ( $\mathrm{V}-\mathrm{OH}$ groups), that proved to be very abundant in this sample based on previous IR studies ${ }^{14}$.

Results of the corresponding curve-fittings are reported in Table 2. With all the V-Si samples the presence of $\mathrm{V}^{3+}($ ca. $516 \mathrm{eV}), \mathrm{V}^{4+}($ ca. $517 \mathrm{~V})$ and $\mathrm{V}^{5+}($ ca. $518 \mathrm{eV})$ was detected. Interestingly, V10Si-i sample contains a higher amount of $\mathrm{V}^{3+}$ species with respect to the samples prepared by FP, probably due to the lower vanadium dispersion reached by impregnation. This fact probably explains the different catalytic performance of the latter sample, as compared to those prepared by FP (vide infra). Although fully oxidised samples were used for XPS analysis, some reduction may in principle occur to surface vanadium oxide under high vacuum, though unlikely at r.t. In any case the comparison above reported among average surface oxidation states of different catalysts, analysed under the same experimental conditions, may be seen as an index of the average oxygen availability (or vanadium oxide reducibility), which may be correlated with catalyst activity and selectivity.

\subsection{XAS analysis}


The XANES spectra and the corresponding derivatives of all the samples are reported in Fig. 5.

The XANES spectrum of $\mathrm{V}_{2} \mathrm{O}_{5}$ is characterised by a typical three peak manifold between 5480 and $5529 \mathrm{eV}$. The same structure was found for almost all the samples, thus labelled $\mathrm{V}_{2} \mathrm{O}_{5}$-like, with three exceptions: i) sample $\mathrm{V} 10 \mathrm{Si}$, for which the XANES manifold is almost identical to that of $\mathrm{AlVO}_{4}$ (called $\mathrm{AlVO}_{4}$-like); ii) samples V10Al and V28Si, which showed a somehow intermediate shape. In addition, the energy edge position is affected by the so called "chemical shift", the edge shifting to lower energies by decreasing the oxidation state of the photoabsorber. For sample V10Si $\left(\mathrm{AIVO}_{4}\right.$-like), the presence of two distinct edges is apparent in both the XANES and in the derivative, indicating thus the occurrence of $\mathrm{V}$ in two distinct oxidation states. Similar evidence, though to a lesser extent, is found also for sample V28Si.

These results are also in line with the previously summarised findings, confirming the higher dispersion of $\mathrm{VO}_{\mathrm{x}}$ species in the FP prepared samples with respect to samples with the same V loading, prepared by impregnation (samples V10Si-i and V10Al-i).

In principle, co-precipitation may be a preparation method more similar to FP than impregnation, starting in every case from a homogeneous mixture of $\mathrm{V}$ and $\mathrm{Si}$ (or $\mathrm{Al}$ ) precursors. This leads to an intimate contact between both precursors, with active phase incorporation into the support matrix. Nevertheless, when comparing sample VAG3 with V10Si, vanadia agglomerates were observed with the former, still present even when halving the V loading (sample VAG1).

The higher $\mathrm{V}$ dispersion attainable with the FP technique may be ascribed to the flash calcination at high temperature. This quenches the system in a metastable structure, where $\mathrm{V}$ remains finely incorporated into the support matrix as in a mixed oxide. Such situation is not easily allowed during the final calcination step of the traditional preparation 
routes, such as co-gelation, which leads to $\mathrm{V}$ segregation and aggregation on the catalyst surface even at relatively low $\mathrm{V}$ loading ${ }^{14-16}$.

The local structures around each sample, as obtained by the EXAFS fittings, are summarised in Tables 3 and 4, with good agreement with literature data ${ }^{38,39}$. Numbers without errors have been kept constant to their crystallographic value during the fitting procedure. This has been done in order to keep at minimum the correlations between fitting parameters during the EXAFS analysis. For the EXAFS fittings, the $\mathrm{V}_{2} \mathrm{O}_{5}$ and $\mathrm{AIVO}_{4}$ spectra, considered as standard materials, have been fitted keeping the distances fixed to their crystallographic values. This gives a value for the $E_{0}$ and amp parameters that can be considered transferable to the spectra of the samples. This has been done in order to keep at a minimum the number of fitting parameters, avoiding unnecessary correlations.

For the $\mathrm{V}_{2} \mathrm{O}_{5}$-like catalysts some examples of fitting results are reported in Fig. 6 .

In the $\mathrm{V}_{2} \mathrm{O}_{5}$ crystal structure, each $\mathrm{V}$ is surrounded by 5 oxygen atoms in a distorted square pyramidal coordination (Nearest Neighbour (NN) shell). A further oxygen ion is found at ca. $2.7 \AA$. The Next Nearest Neighbour (NNN) shell is made up by 2 vanadium atoms located at ca. $3.1 \AA$. Further three $\mathrm{V}$ atoms are found at ca. $3.5 \AA$. This picture may be formally represented as in Fig. 7a. The nearest oxygen may be described as a doubly bonded oxygen (label 1 in Fig. $7 a-c$ ), also according to literature data ${ }^{39}$. In addition, three near $(<2 \AA)$ and two far $(>2 \AA)$ oxygen atoms are found (labels 2,3 and 4,5, respectively, in Fig. $7 a, b)$. It should be underlined that the oxygen atoms surrounding $\mathrm{V}$ and depicted as bound to the photoabsorber, may be only interacting with it in some way, not necessarily by more or less covalent bonds. The V-O distances reported in Table 3 are in fairly good agreement with those reported in ${ }^{38}$ and could be interpreted also on the basis of the proposed "umbrella-type" $\mathrm{VO}_{x}$ clusters ${ }^{38,40-42}$.

The local structure typical of $\mathrm{V}_{2} \mathrm{O}_{5}$, though more or less distorted, characterised all the samples prepared by impregnation or by FP at high V loading, as well as those prepared 
by co-gelation, even at the lowest $\mathrm{V}$ concentration (6.7 wt\%). The oxygen distance was a bit different for sample V50Si and V50Al, more likely represented as in Fig. 7c.

A different structure characterised the so-called $\mathrm{AIVO}_{4}$-like samples (Fig. 7d,e). Indeed, no $\mathrm{V}$ ions can be inferred nearby the photoabsorber. Furthermore, in the Al containing samples some Al can be found around V. In addition, the $\mathrm{V}$ site is surrounded by oxygen atoms in a more ordered array than the $\mathrm{V}_{2} \mathrm{O}_{5}$-like samples.

Another very interesting feature is the much lower $\mathrm{V}-\mathrm{O}$ distance determined for the silica supported V10Si sample with respect to V10Al. This feature may be related to a stronger V-O interaction, which in principle should hinder oxygen release from the catalyst, so decreasing reactants conversion, but eventually improving selectivity towards propylene. Something similar has been already observed by means of EPR analysis ${ }^{14-16}$, though in such case referring to $\mathrm{V}(\mathrm{IV})$ ions, only.

It should be remarked that no definite correlation has been so far established on the relationship between vanadyl oxygen and activity/selectivity ${ }^{43}$. For instance, a short, terminal $\mathrm{V}=\mathrm{O}$ bond has been proposed ${ }^{44}$ for hydrogen abstraction from $\mathrm{C}-\mathrm{H}$ bond, whereas $\mathrm{V}-\mathrm{O}-\mathrm{V}$ oxygen bridges participate in the next steps when water is formed. By contrast, Kung et al. ${ }^{45}$ proposed the terminal vanadyl bond as responsible for total oxidation and the bridged oxygen atoms as selective sites for propene. Alternatively, it was also proposed that $\mathrm{V}-\mathrm{O}$ bonds in tetrahedral or octahedral coordination are responsible for selective oxidation, whereas the $\mathrm{V}-\mathrm{O}$ bonds near a vanadyl oxygen lead to oxygenate products ${ }^{46}$. $\mathrm{V}=\mathrm{O}$ bond strength has been correlated with activity in $\mathrm{ODH}$ reactions ${ }^{13}$, but this results has been explicitly criticised by Wachs et al. on the basis of a probe methanol $\mathrm{ODH}$ reaction ${ }^{47}$, excluding any direct influence of $\mathrm{V}=\mathrm{O}$ bond length or strength in ODH performance.

In this confusing panorama, the present findings seem to support and generalise a correlation between the $\mathrm{V}^{\mathrm{n}+}-\mathrm{O}$ bond length (i.e. strength) and catalyst selectivity. 
Furthermore, it is in line with very recent DFT calculations ${ }^{48}$ on propane ODH over a model $\mathrm{V}_{2} \mathrm{O}_{5}(001)$ surface, which definitely confirm the role of the vanadyl oxygen in the reaction ${ }^{49,50}$, particularly for the consecutive oxidation of propene ${ }^{48}$. By contrast higher selectivity is predicted when the oxidant is a bridging oxygen. Increasing reactivity in the case of bridging oxygens was also observed by Lacheen and Iglesia ${ }^{51}$. Also, increasing $\mathrm{V}=\mathrm{O}$ bond strength has been reported ${ }^{18}$ with increasing the polymerization degree of vanadium over alumina support for catalysts used in the $\mathrm{ODH}$ of ethane.

\section{5 - Catalyst acidity as studied by means of IR spectroscopy}

A thorough IR spectroscopy study of the present catalysts was reported elsewhere ${ }^{14,15}$ : in summary, different $\mathrm{OH}$ species were detected at the surface of $\mathrm{V} 10 \mathrm{Si}$, namely isolated $\mathrm{SiOH}, \mathrm{H}$-bonded $\mathrm{SiOH}$ and $\mathrm{V}-\mathrm{OH}$. Such hydroxyls were characterized by different acidic strength in the order: isolated $\mathrm{SiOH}<\mathrm{H}$-bonded $\mathrm{SiOH}<<\mathrm{V}-\mathrm{OH}$. Their acidic strength was measured by the shift of the $\mathrm{OH}$ stretch band after $\mathrm{CO}$ adsorption at $-196^{\circ} \mathrm{C}(\Delta \mathrm{v})$, the larger the shift the larger the acidity of the Brønsted site ${ }^{52}$.

Another possible means to assess the surface acidity is adsorption of ammonia: the interaction with $\mathrm{NH}_{3}$ being stronger than with $\mathrm{CO}$, adsorption measurements may be run at r.t. Ammonia molecules may interact with both Lewis acidic sites, by forming acid-base adducts, and Brønsted sites, with formation of ammonium species, characterized by distinct spectroscopic features. In particular, the free ammonium ion is characterized by a band at $1410 \mathrm{~cm}^{-1}$ due to its bending vibration ${ }^{53}$. Fig. 8 reports difference spectra recorded after dosing ca. 0.4 mbar $\mathrm{NH}_{3}$ at r.t. on the samples outgassed at $150^{\circ} \mathrm{C}$ : the band at $1608 \mathrm{~cm}^{-1}$ is assigned to ammonia molecules coordinated to surface vanadium ions performing as Lewis acidic sites; the band at lower wavenumbers is assigned to the bending vibration of ammonium ions formed after reaction of ammonia with Brønsted 
hydroxyls. The position of the latter band changes from sample to sample: with V10Si it is seen at $1448 \mathrm{~cm}^{-1}$, whereas it is red-shifted at higher vanadium loadings, that is when $\mathrm{V}_{2} \mathrm{O}_{5}$ is present. Fig. 9 reports a chart in which the $\Delta v$ measured by $\mathrm{CO}$ adsorption ${ }^{14}$, which is an actual measure of acidity according to the literature ${ }^{52}$, is reported as a function of the position of the ammonium band: interestingly, a linear correlation is found. Therefore, it is possible to infer that in $\mathrm{V} 10 \mathrm{Si}$, in which high vanadium dispersion is obtained, weaker acidic sites are present, with respect to the other samples, were $\mathrm{V}_{2} \mathrm{O}_{5}$ was also present. The same experiment was run with $\mathrm{V} / \mathrm{Al}$ samples, and the corresponding spectra are reported in Fig. 10: the features of ammonia interacting with Lewis and Brønsted sites are seen at 1613 and $1426-1422 \mathrm{~cm}^{-1}$, respectively. For this set of samples, however, it was not possible to make an analogous discussion on the role of V-sites acidity and its correlation with selectivity (vide infra), due to the fact that the $\mathrm{Al}_{2} \mathrm{O}_{3}$ support itself contains both Lewis and Brønsted sites, hardly distinguishable from those due to vanadium. However, it may be inferred that also the acidic properties of the support may play a role on catalytic activity, as already discussed elsewhere ${ }^{18,54}$.

\section{6 - Correlation with activity data.}

As pointed out in the Introduction, selectivity is one of the key-points for ODH reaction and every factor decreasing full propene oxidation may help to increase such parameter. When looking at the catalytic performance of these samples, a different behaviour was observed depending on the reaction mode ${ }^{14-16}$.

Under aerobic conditions (co-feed mode), propane conversion rate increased as expected with reaction temperature (Fig. 11a), but the effect of temperature was much more evident for silica-supported samples than for the alumina based ones, which showed significant propane conversion even at $400^{\circ} \mathrm{C}$. Furthermore, for the latter oxygen conversion was full 
at the lowest testing temperature, inducing limited variation of conversion with increasing temperature. Propane conversion rate normalised per $\mathrm{g}$ of $\mathrm{V}$ decreased with increasing $\mathrm{V}$ loading and showed very similar for both supports, irrespectively for the preparation method. In the overall temperature range, high $\mathrm{V}$ loading corresponded to depressed selectivity to propylene, the catalyst being predominantly active for full oxidation ${ }^{14-16}$.

The productivity of propylene is reported in Fig. 11b. It was higher for the alumina supported samples at low temperature, resulted driven by the higher propane conversion, but at the highest testing temperature the higher selectivity to propylene of the silica supported samples allowed to reach higher productivities. The latter parameter was quite independent on $\mathrm{V}$ loading, since the data were normalised on $\mathrm{V}$ mass, and on the preparation method.

Therefore it may be inferred from the present data that a higher $\mathrm{V}$ dispersion, i.e. its incorporation and stabilisation into the support matrix, leads to an increase of selectivity to propylene under cofeed conditions, especially at low operating temperature. The reason can be ascribed to the formation of monovanadate species stabilised by the incorporation of $\mathrm{V}$ into the support during catalyst preparation. This result confirms the known importance of $\mathrm{V}$ site-isolation in improving selectivity for the $\mathrm{ODH}$ reaction ${ }^{2,3,18,24,54-58}$.

When testing catalyst activity in redox mode, the fully oxidised catalyst was fed with pure propane at fixed temperature (e.g. at $550^{\circ} \mathrm{C}$ ) for 15 minutes. Propane conversion progressively decreased with time-on-stream due to oxygen depletion from the catalyst and contemporarily propylene selectivity increased ${ }^{14-16}$. However, the most interesting points to characterise the performance refer to activity of the fully oxidised catalysts, as reported in Fig.12. Propane conversion rate (Fig. 12a) decreased with increasing $\mathrm{V}$ loading irrespectively of the support and preparation procedure, whereas it was higher for samples prepared by co-gelation, followed by impregnation and last by the FP ones. 
As for propylene productivity under anaerobic conditions (Fig. 12b), it decreased markedly with increasing $\mathrm{V}$ loading, indicating a very poor selectivity to propylene at the highest $\mathrm{V}$ content. Samples prepared by impregnation demonstrated lower selectivity, thus giving lower propylene productivity than the FP homologues, in spite of their higher conversion rate. Again, samples prepared by co-gelation exhibited the highest productivity, essentially determined by their higher conversion rate.

In principle, co-gelation could induce similarly high $\mathrm{V}$ dispersion than FP. However, the present EXAFS data assess the presence of $\mathrm{V}_{2} \mathrm{O}_{5}$ even for sample VAG1, characterised by much lower $\mathrm{V}$ loading than $\mathrm{V} 10 \mathrm{Si}$. Isolated monovanadate species have been also evidenced by Raman spectroscopy for sample VAG1 only, $\mathrm{V}_{2} \mathrm{O}_{5}$ characterising sample VAG3 ${ }^{30,59}$. A deeper investigation of the nature of $\mathrm{V}_{2} \mathrm{O}_{5}$ aggregates in VAG1 allowed to conclude that they were not exposed on catalyst surface, but embedded into the support matrix and scarcely available for the reactants. Accordingly, much higher selectivity at isoconversion has been already reported for sample VAG1 than for VAG3 ${ }^{30,59}$. Therefore, we may further conclude that the best results in terms of selectivity could be reached when site isolation was successfully reached by proper preparation procedure.

Interestingly, a preparation procedure similar to the FP one here proposed, has been suggested also by some other authors ${ }^{60}$. They substantially agree on the validity of this preparation method to achieve high $\mathrm{V}$ dispersion. In such case the mechanism of particle formation was different from ours, due to the employment of different precursors, solvents and pressure drop across the nozzle. Surface area as high as $300 \mathrm{~m}^{2} \mathrm{~g}^{-1}$ has been reported for different $\mathrm{FSP}$-made $\mathrm{V} / \mathrm{SiO}_{2}$ samples. Anyway, in spite of the much higher surface area of such samples, it is worth noticing that monovanadate species mainly constituted samples with $\mathrm{V}$ loading lower than 20 wt\%, while $\mathrm{V}_{2} \mathrm{O}_{5}$ was observed over $25 \mathrm{~V}$ $w t \%$ as in the present case, in spite of the lower specific surface area of the present samples. However, Schimmoeller et al. ${ }^{60}$ propose a picture of $\mathrm{VO}_{\mathrm{x}}$ species fully exposed 
on support surface and deny the hypothesis that vanadium incorporation into the support matrix may somehow occur. The present XAS data seem in contrast with such statement, demonstrating that $\mathrm{AlVO}_{4}$-like samples, i.e. with $\mathrm{V}$ incorporation into the support, may exist also with the silica support, provided that the $\mathrm{V}$ loading is not too high. The substantial similarity among the two sets of catalysts, the present ones and those reported in ref. 60 , is also testified by their catalytic activity. Though the activity tests have been collected under different reaction conditions and in co-feed mode only, the conversion and selectivity trend with respect to temperature and $\mathrm{V}$ loading is similar to the data already reported by us ${ }^{14}$. Unfortunately, a rigorous comparison of results is complex, since their data were collected at very different contact time than in the present case. Roughly, the productivity of propylene at $550^{\circ} \mathrm{C}$ over the present $\mathrm{V} 10 \mathrm{Si}$ sample was $0.2 \mathrm{~kg} / \mathrm{h} \mathrm{kg}$ cat, i.e. one order of magnitude lower than that of a similar catalyst $\left(1.2 \mathrm{~kg} / \mathrm{h} \mathrm{kg}_{\text {cat }}\right)$ reported in ${ }^{60}$. Such difference is fully explainable on the basis of the much lower contact time used by them. Indeed, when increasing contact time they observed a rapid drop of selectivity which brings their results fairly near to the present ones.

A direct influence of $\mathrm{V}$ dispersion on catalyst acidity also appears from the data here reported, different for the silica or alumina supported samples. Surface acidity diminished with increasing $\mathrm{V}$ dispersion for the $\mathrm{V}$-Si series, while increased for the $\mathrm{V}$-Al ones.

This may be related to the local structure hypothesised for both $\mathrm{AlVO}_{4}$-like samples, characterised by high $\mathrm{V}$ dispersion, which may lead to the formation of different acid sites, which tentative picture is reported in Fig. 13. For catalyst V10Si, OH surface sites form in very high concentration, as confirmed by FTIR analysis ${ }^{14}$, and they were characterised by low acidity, so improving selectivity to propylene. Fig. 14 reports selectivity to propene at iso-conversion $(12 \% \pm 1)$ under anaerobic conditions $\left(550^{\circ} \mathrm{C}\right)$ and different times on stream: it decreased in the series V10Si > V28Si > V50Si > V10Si-i, with a tight 
relationship with dispersion and acidity. Higher selectivity was obtained with the sample containing highly dispersed vanadium sites and showing the lowest acidity, as well.

By contrast, in the case of V10Al the acid site nature was found much more similar to those found in zeolites, so impressively more acidic than the silica based ones, further explaining the lower selectivity of alumina based sample, irrespectively of $\mathrm{V}$ concentration. This point does not represent a real problem when cofeeding propane and oxygen, since acidity is mainly related to catalyst coking. Indeed, olefins may polymerise over acid sites leasing to coke deposition and the addition of oxygen in the feed may help in cleaning the surface.

Finally, the here reported correlations between $\mathrm{V}$ oxidation state and surface acidity and selectivity seem to conflict with the conclusions reported in a previous work by Tian et al. ${ }^{8}$, where it is stated that the catalytic TOF for propane ODH to propene, which only requires one surface $\mathrm{VO}_{4}$ unit, is independent of the extent of polymerization of the surface $\mathrm{VO}_{4}$ species, the $E_{g}$ value, the surface Brønsted acidity, and the reducibility of the surface vanadia species, and is only a function of the specific oxide support.

Finally, from the XPS compositional analysis, an average oxidation state of vanadium was calculated (last column in Table 2), showing that the average BE of vanadium was higher in the sample with the best catalytic performances (V10Si). In Fig. 15, the values of selectivity to propene in Fig. 14 are reported as a function of the average BE values in Table 2: interestingly, a linear correlation is found showing that, for a homogeneous series of samples supported over $\mathrm{SiO}_{2}$, selectivity increases with the average vanadium oxidation state, which may also mean a harder reducibility of the active site. Such iso-conversion values were reached after different times-on-stream, so in principle at different oxidation state of $\mathrm{V}$ in different materials. In order to elucidate this latter point, Fig. 15 also reports the initial selectivity (time-on-stream $=1 \mathrm{~min}$ ) under anaerobic conditions and $\mathrm{T}=550^{\circ} \mathrm{C}$ for V10Si (14\% conversion) and V10Si-i (16\% conversion), i.e. the two samples which 
have the same $\mathrm{V}$ content. It is interesting to notice that for $\mathrm{V} 10 \mathrm{Si}$, the two measured values were very similar, in that the selectivity did not change much, whereas the initial selectivity with V10Si-i was lower, as previously reported [14], and increased much with time. In conclusion, it appears that site isolation helps improving the selectivity to propylene. This may be correlated to vanadium oxide reducibility and acidity, at least in the case of silicasupported samples.

The present data insert in the complex panorama sketched in Table 5, where some of the literature reports on the nature and role of active sites for this application are summarized.

\section{4 - CONCLUSIONS}

A possible correlation between the local structure of the $\mathrm{V}$ active sites and activity and selectivity for propane ODH has been proposed. Dispersed monovanadate species seem the most selective to propylene, but such high dispersion is hardly achieved with traditional preparation methods, except when very low $\mathrm{V}$ amount is used. The main drawback of the latter approach is that a decrease of $\mathrm{V}$ loading introduces a dependence of selectivity by different factors, such as support nature and acidity.

The proposed flame pyrolysis method for the preparation of silica and alumina supported V-based catalysts allows to attain very high vanadium dispersion at relatively high loading, as demonstrated by the present XAS and TEM analyses, with respect to other methods, such as impregnation or co-gelation. $\mathrm{V}$ dispersion showed also an interesting correlation with surface acidity and $\mathrm{V}$ oxidation state, at least for the silica-supported samples, which in turn may explain the observed selectivity trend. Finally, the possible structure of $\mathrm{V}$ active sites has been proposed on the basis of the refinement of EXAFS data.

\section{REFERENCES}


1. Chenier, P.J. Survey of industrial Chemistry, 3rd Ed.; Kluwer Academic-Plenum Publishers, 2002.

2. Cavani, F.; Ballarini, N.; Cericola, A. Catal. Today 2007, 127, 113-131.

3. Argyle, M.D.; Chen, K.; Bell, A.T.; Iglesia, E. J. Catal. 2002, 208, 139-149.

4. Elam, J.W.; Pellin, M.J.; Libera, J.A.; Stair, P.C.; Zajac, G.; Cohen, S.A. US pat. Appl. 20090191101-A1, 2009, to UChicago Argonne, LLC.

5. Brophy, J.H. US pat. $7,402,719,2008$, to Velocys.

6. Rozanska, X.; Fortrie, R.; Sauer, J. J. Phys. Chem. C 2007, 111, 6041-6050.

7. Chen, K.D.; Bell, A.T.; Iglesia, E. J. Catal. 2002, 209, 35-42.

8. Tian, H.; Ross, E.I.; Wachs, I.E. J. Phys. Chem. B 2006, 110, 9593-9600.

9. Dinse, A.; Ozarowski, A.; Hess, C.; Schomäcker, R.; Dinse, K.-P. J. Phys. Chem. C 2008, 112,17664-17671.

10. Koranne, M.M.; Goodwin, J.G., Jr.; Marcelin, G. J.Catal. 1994, 148, 369-377.

11. Haber, J.; Kozlowska, A.; Kozłowski, R. J.Catal. 1986, 102, 52-63.

12. Erdohelyi, A.; Solymosi, F. J. Catal. 1990, 123, 31-42.

13. Trifirò, F.; Centola, P.; Pasquon, I. J. Catal. 1968, 10, 86-88.

14. Rossetti, I.; Fabbrini, L.; Ballarini, N.; Oliva, C.; Cavani, F.; Cericola, A.; Bonelli, B.; Piumetti, M.; Garrone, E.; Dyrbeck, H.; et al. J. Catal. 2008, 256, 45-61.

15. Rossetti, I.; Fabbrini, L.; Ballarini, N.; Oliva, C.; Cavani, F.; Cericola, A.; Bonelli, B.; Piumetti, M.; Garrone, E.; Dyrbeck, H.; et al. Catal. Today 2009, 141, 271-281.

16. Oliva, C.; Cappelli, S.; Rossetti, I.; Ballarini, N.; Cavani, F.; Forni, L. Chem. Eng. J. 2009, 154, 131-136.

17. Wachs, I.E. Appl. Catal. A: Gen. 2011, 391, 36-42.

18. Martìnez-Huerta, M.V.; Gao, X.; Tian, H.; Wachs, I.E.; Fierro, J.L.G.; Bañares, M.A. Catal. Today 2006, 118, 279-287. 
19. Argyle, M.D.; Chen, K.; Resini, C.; Krebs, C.; Bell, A.T.; Iglesia, E. J. Phys. Chem. $B, 2004,108,2345-2353$.

20. Gao, X.; Bare, S.R.; Fierro, J. L. G.; Wachs, I.E. J. Phys. Chem. B 1999, 103, 618629.

21.Dinse, A.; Khennache, S.; Frank, B.; Hess, C.; Herbert, R.; Wrabetz, S.; Schloegl, R.; Schomaecker, R. J. Molec. Catal. A 2009, 307, 43-50.

22. Dinse, A.; Schomaecker, R.; Bell, A.T Phys. Chem. Chem. Phys. 2009, 11, 61196124.

23. Gazzoli, D.; De Rossi, S.; Ferraris, G.; Mattei, G.; Spinicci, R.; Valigi, M. J. Molec. Catal. A 2009, 310, 17-23.

24. Kondratenko, E.V.; Steinfeldt, N.; Baerns, M. Phys. Chem. Chem. Phys. 2006, 8, 1624-1633.

25. Chiarello, G.L.; Rossetti, I.; Forni, L. J. Catal. 2005, 236, 251-261.

26. Chiarello, G.L.; Rossetti, I.; Lopinto, P.; Migliavacca, G.; Forni, L. Catal. Today 2006, 117, 549-553.

27. Chiarello, G.L.; Rossetti, I.; Forni, L.; Lopinto, P.; Migliavacca, G. Appl. Catal. B Environ. 2007, 72, 218-226.

28. Chiarello, G.L.; Rossetti, I.; Forni, L.; Lopinto, P.; Migliavacca, G. Appl. Catal. B Environ. 2007, 72, 227-232.

29. Giacomuzzi, R.A.M.; Portinari, M.; Rossetti, I.; Forni, L. Stud. Surf. Sci. and Catal. $2000,130,197-202$.

30. Ballarini, N.; Cavani, F.; Ferrari, M.; Catani, R.; Cornaro, U. J. Catal. 2003, 213, 95102

31. Advanced Selected Powder Diffraction Data, Miner. DBM (1-40), J.C.P.D.S., Swarthmore, PA, 1974-1992.

32. Newville, M. J. Synchrotron Rad. 2001, 8, 322-324. 
33. Ravel, B.; Newville, M. J. Synchrotron Rad. 2005, 12, 537-541.

34. Khodakov, A.; Olthof, B.; Bell, A.T.; Iglesia, E. J. Catal. 1999, 181, 205-216 and references therein.

35. Bukallah, S. B.; Bumajdad, A.; Khalil, K. M. S.; Zaki, M. I. Appl. Surf. Sci. 2010, 256, 6179-6185.

36. Lorite, I.; Martín-González, M.S.; Romero, J.J.; García, M.A.; Fierro, J. L. G.; Fernández, J. F. Ceramics Int. 2012, 38, 1427-1434.

37. Bar, M. R.; Sauer, J. Chem. Phys. Lett. 1994, 226, 405-412.

38. van Lingen, J.N.J.; Gijzeman, O.L.J.; Weckhuysen, B.M.; van Lenthe, J.H. J. Catal. 2006, 239, 34-41.

39. Brázdová, V.; Ganduglia-Pirovano, M.V.; Sauer, J. J. Phys. Chem. B 2005, 109, 394-400.

40.Gijzeman, O.L.J.; van Lingen, J.N.J.; van Lenthe, J.H.; Tinnemans, S.J.; Keller, D.E.; Weckhuysen, B.M. Chem. Phys. Lett. 2004, 397, 277-281.

41. Keller, D.E.; Airaksinen, S.M.K.; Outi Krause, A.; Weckhuysen, B.M.; Koningsberger, D.C. J. Am. Chem. Soc. 2007, 129, 31893197.

42. Keller, D.E.; Visser, T.; Soulimani, F.; Koningsberger, D.C.; Weckhuysen, B.M. Vibrational Spectroscopy 2007, 43, 140-151.

43. Grabowski, R. Catal. Rev. 2006, 48, 199-268.

44. Sew Hew Sam, D.; Soenen, V.; Volta, J.C. J. Catal. 1990, 123, 417-435.

45. Kung, M.C.; Kung, H.H. J. Catal. 1992, 134, 668-677.

46. Yoon, Y.S.; Ueda, W.; Moro-oka, Y. Catal. Lett. 1995, 35, 57-64.

47. Routray, K.; Briand, L.E.; Wachs, I.E. J. Catal. 2008, 256, 145-153.

48. Dai, G.-L.; Li, Z.-H.; Lu, J.; Wang, W.-N.; Fan, K.-N. J. Phys. Chem. C 2012, 116, 807-817. 
49. Cheng, M.-J.; Chenoweth, K.; Oxgaard, J.; van Duin, A.; Goddard III, W.A. J. Phys. Chem. C 2007, 111, 5115-5127.

50. Redfern, P.C.; Zapol, P.; Sternberg, M.; Adiga, S. P.; Zygmunt, S. A.; Curtiss, L. A. J. Phys. Chem. B 2006, 110, 8363-8371.

51. Lacheen, H.S.; Iglesia, E. J. Phys. Chem. B 2006, 110, 54625472.

52. Zecchina, A.; Areán, C.O. Chem. Soc. Rev. 1996, 25, 187-197.

53.Zecchina, A.; Marchese, L.; Bordiga, S.; Pazè, C.; Gianotti, E. J. Phys. Chem. B 1997, 101, 10128-10135.

54. Blasco, T.; Galli, A.; López Nieto, J. M.; Trifirò, F. J. Catal., 1997, 169, 203-211.

55. Bulánek, R.; Kalužová, A.; Setnička, M.; Zukal, A.; Cičmanec, P.; Mayerová, J. Catal. Today, 2012, 179, 149-158.

56. Balderas-Tapia, L.; Hernández-Pérez, I.; Schacht, P.; Córdova, I.R.; Aguilar-Ríos, G.G. Catal. Today, 2005, 107-108, 371-376.

57. Steinfeldt, N.; Müller, D.; Berndt, H. Appl. Catal. A: Gen. 2004, 272, 201-213.

58. Gruene, P.; Wolfram, T.; Pelzer, K.; Schlögl, R.; Trunschke, A. Catal. Today 2010, $157,137-142$.

59. Ballarini, N.; Cavani, F.; Cericola, A.; Cortelli, C.; Ferrari, M.; Trifirò, F.; Capannelli, G.; Comite, A.; Catani, R.; Cornaro, U. Catal. Today, 2004, 91-92, 99-104.

60. Schimmoeller, B.; Jiang, Y.; Pratsinis, S.E.; Baiker, A. J. Catal., 2010, 274, 64-75. 


\section{TABLES}

Table 1: Catalysts composition and main physical chemical properties.

\begin{tabular}{|c|c|c|c|c|}
\hline Sample & Preparation & V loading (wt\%) & $\operatorname{SSA}\left(\mathrm{m}^{2} / \mathrm{g}\right)$ & XRD phases ${ }^{31}$ \\
\hline $\mathrm{AlVO}_{4}{ }^{\mathrm{a}}$ & FP & 35.9 & 21 & $\mathrm{AlVO}_{4}$ \\
\hline V10Si & $\mathrm{FP}$ & 10.0 & 75 & $A^{c}$ \\
\hline V10Si-i & Impregnation $^{\mathrm{b}}$ & 10.0 & - & $\mathrm{A}+\mathrm{V}_{2} \mathrm{O}_{5}$ \\
\hline V10Al & FP & 10.0 & 19 & $\delta$ or $\eta-\mathrm{Al}_{2} \mathrm{O}_{3}$ \\
\hline V10Al-i & Impregnation $^{b}$ & 10.0 & - & $\delta$ or $\eta-\mathrm{Al}_{2} \mathrm{O}_{3}+\mathrm{V}_{2} \mathrm{O}_{5}$ \\
\hline V28Si & FP & 28.4 & 80 & $\mathrm{~A}+\mathrm{V}_{2} \mathrm{O}_{5}$ \\
\hline V50Si & FP & 50.0 & 46 & $\mathrm{~A}+\mathrm{V}_{2} \mathrm{O}_{5}$ \\
\hline V50Al & FP & 50.0 & 27 & $\delta$ or $\eta-\mathrm{Al}_{2} \mathrm{O}_{3}+\mathrm{V}_{2} \mathrm{O}_{5}$ \\
\hline VAG1 & Co-gel & 6.7 & 490 & $\mathrm{~A}+\mathrm{V}_{2} \mathrm{O}_{5}$ \\
\hline VAG3 & Co-gel & 15.0 & 240 & $\mathrm{~A}+\mathrm{V}_{2} \mathrm{O}_{5}$ \\
\hline
\end{tabular}

${ }^{a}$ Calcined in air after FP preparation at $600^{\circ} \mathrm{C}$ for $1 \mathrm{~h}$

b On FP-prepared supports

${ }^{\mathrm{c}} \mathrm{A}=$ Amorphous

Table 2: Results of curve-fittings on $\mathrm{V}_{2 p} 3 / 2$ peaks in $\mathrm{XP}$ spectra of $\mathrm{V} / \mathrm{SiO}_{2}$ samples: maximum position $(\mathrm{eV})$ is reported along with the corresponding atomic percentage for $\mathrm{V}^{3+}, \mathrm{V}^{4+}$ and $\mathrm{V}^{5+}$ species. In the last column, weighted average values of Binding Energy (BE) are reported, as calculated by taking into account both maximum position and atomic percentage.

\begin{tabular}{|c|c|c|c|c|c|c|c|}
\hline Sample & $\begin{array}{c}\mathbf{V}^{\mathbf{3 +}} \\
\text { (\% atom) }\end{array}$ & $\begin{array}{c}\mathbf{V}^{\mathbf{3 +}} \\
\mathbf{B E}(\mathbf{e V})\end{array}$ & $\begin{array}{c}\mathbf{V}^{4+} \\
\text { (\% atom) }\end{array}$ & $\begin{array}{c}\mathbf{V}^{4+} \\
\mathbf{B E}(\mathbf{e V})\end{array}$ & $\begin{array}{c}\mathbf{V}^{5+} \\
\text { (\% atom) }\end{array}$ & $\begin{array}{c}\mathbf{V}^{\mathbf{5}} \\
\mathbf{B E}(\mathbf{e V})\end{array}$ & $\begin{array}{c}\text { Average } \\
\mathbf{B E}(\mathbf{e V})\end{array}$ \\
\hline V10Si & 15.44 & $516.3(6)$ & 43.79 & $517.6(6)$ & 40.77 & $519.0(3)$ & $518.0(2)$ \\
\hline V10Si-i & 32.77 & $516.0(9)$ & 60.35 & $517.4(1)$ & 6.88 & $518.7(1)$ & $517.0(7)$ \\
\hline V28Si & 16.23 & $516.2(0)$ & 58.93 & $517.4(6)$ & 24.93 & $518.2(9)$ & $517.9(3)$ \\
\hline V50Si & 9.05 & $516.2(9)$ & 73.74 & $517.1(7)$ & 17.21 & $518.5(2)$ & $517.7(2)$ \\
\hline
\end{tabular}


Table 3: $\mathrm{V}$ local structure from EXAFS data for $\mathrm{V}_{2} \mathrm{O}_{5}$-like samples.

\begin{tabular}{|c|c|c|c|c|}
\hline Catalyst & Shell & $r(\AA)$ & $s^{2}\left(\AA^{-2}\right)$ & $\mathrm{N}$ \\
\hline \multirow{7}{*}{$\mathrm{V}_{2} \mathrm{O}_{5}$} & $\mathrm{~V}-\mathrm{Ov}$ & 1.5759 & $0.000(7)$ & 1 \\
\hline & $\mathrm{V}-\mathrm{Ob}$ & 1.7785 & $0.00(1)$ & 1 \\
\hline & $\mathrm{V}-\mathrm{Oc}$ & 1.8775 & $0.008(8)$ & 2 \\
\hline & $\mathrm{V}-\mathrm{Oc}$ & 2.0174 & $0.01(2)$ & 1 \\
\hline & V-Ov & 2.7927 & $0(6)$ & 1 \\
\hline & V-V & 3.0818 & $0.01(1)$ & 2 \\
\hline & $\mathrm{V}-\mathrm{V}$ & 3.564 & $0.01(1)$ & 3 \\
\hline \multirow{8}{*}{ V10Al-i } & & & & \\
\hline & V-Ov & 1.5759 & $0.003(5)$ & 1 \\
\hline & $\mathrm{V}-\mathrm{Ob}$ & 1.7785 & $0.01(2)$ & 1 \\
\hline & $\mathrm{V}-\mathrm{Oc}$ & 1.8775 & $0.009(7)$ & 2 \\
\hline & $\mathrm{V}-\mathrm{Oc}$ & 2.0174 & $0.01(2)$ & 1 \\
\hline & $\mathrm{V}-\mathrm{Ov}$ & 2.7927 & 0.441 & 1 \\
\hline & V-V & $3.13(5)$ & $0.007(7)$ & 2 \\
\hline & $\mathrm{V}-\mathrm{V}$ & $3.494(9)$ & $0.02(1)$ & 3 \\
\hline \multirow{8}{*}{ V10Si-i } & & & & \\
\hline & $\mathrm{V}-\mathrm{Or}$ & $1.58(7)$ & $0.001(6)$ & 1 \\
\hline & $\mathrm{V}-\mathrm{Ob}$ & 1.881) & $0.00(3)$ & 1 \\
\hline & $\mathrm{V}-\mathrm{Oc}$ & 1.8731 & $0.01(5)$ & 2 \\
\hline & $\mathrm{V}-\mathrm{Oc}$ & 2.1264 & $0.00(2)$ & 1 \\
\hline & $\mathrm{V}-\mathrm{Ov}$ & 2.8957 & $0.00(3)$ & 1 \\
\hline & $\mathrm{V}-\mathrm{V}$ & $3.13(7)$ & $0.01(1)$ & 2 \\
\hline & $\mathrm{V}-\mathrm{V}$ & $3.4(1)$ & $0.02(1)$ & 3 \\
\hline & & & & \\
\hline \multirow{7}{*}{ V28Si } & $\mathrm{V}-\mathrm{Ov}$ & $1.59(3)$ & $0.007(4)$ & 1 \\
\hline & $\mathrm{V}-\mathrm{Ob}$ & $1.8(1)$ & $0.016(7)$ & 1 \\
\hline & $\mathrm{V}-\mathrm{Oc}$ & 1.8775 & $0.016(7)$ & 2 \\
\hline & $\mathrm{V}-\mathrm{Oc}$ & 2.0174 & \begin{tabular}{|l|}
$0.016(7)$ \\
\end{tabular} & 1 \\
\hline & $\mathrm{V}-\mathrm{Ov}$ & 2.7927 & 0.431 & 1 \\
\hline & V-V & $3.06(5)$ & $0.014(6)$ & 2 \\
\hline & $\mathrm{V}-\mathrm{V}$ & $3.4(2)$ & 0.04(3) & 3 \\
\hline \multirow{7}{*}{ V50Al } & V-Ov & $15(1)$ & 0 & 1 \\
\hline & $\mathrm{V}-\mathrm{Ob}$ & $1.66(5)$ & 0.002 & 1 \\
\hline & $\mathrm{V}-\mathrm{Oc}$ & $1.93(6)$ & $0.005(5)$ & 2 \\
\hline & $\mathrm{V}-\mathrm{Oc}$ & 1.8274 & $0.005(5)$ & 1 \\
\hline & $\mathrm{V}-\mathrm{Ov}$ & 2.8047 & $0.01(8)$ & 1 \\
\hline & $\mathrm{V}-\mathrm{V}$ & $3.12(6)$ & $0.004(7)$ & 2 \\
\hline & V-V & $3.45(3)$ & $0.02(3)$ & 3 \\
\hline & & & & \\
\hline \multirow{4}{*}{ V50Si } & V-Ov & $1.6(1)$ & $0.02(5)$ & 1 \\
\hline & $\mathrm{V}-\mathrm{Ob}$ & $1.92(5)$ & $0.003(5)$ & 1 \\
\hline & $\mathrm{V}-\mathrm{Oc}$ & 1.7375 & $0.04(7)$ & 2 \\
\hline & $\mathrm{V}-\mathrm{Oc}$ & 1.8774 & $0.04(7)$ & 1 \\
\hline
\end{tabular}

28 


\begin{tabular}{|c|c|c|c|c|}
\hline \multirow{4}{*}{} & V-OV & 2.7767 & $0.01(2)$ & 1 \\
\cline { 2 - 5 } & V-V & $3.09(3)$ & $0.008(5)$ & 2 \\
\cline { 2 - 5 } & V-V & $3.4(1)$ & $0.01(2)$ & 1 \\
\hline \multirow{4}{*}{ VAG1 } & V-Ov & $1.56(3)$ & $0.004(3)$ & 1 \\
\cline { 2 - 5 } & V-Ob & $1.7(1)$ & $0.01(1)$ & 1 \\
\cline { 2 - 5 } & V-Oc & 1.8775 & $0.01(1)$ & 2 \\
\cline { 2 - 5 } & V-Oc & 2.0174 & $0.01(1)$ & 1 \\
\cline { 2 - 5 } & V-Ov & 2.7927 & 0.346 & 1 \\
\cline { 2 - 5 } & V-V & $3.07(3)$ & $0.011(4)$ & 2 \\
\cline { 2 - 5 } & V-V & $3.4(1)$ & $0.03(2)$ & 3 \\
\hline \multirow{4}{*}{ VAG3 } & V-Ov & $1.5(1)$ & $0.01(2)$ & 1 \\
\cline { 2 - 5 } & V-Ob & $1.7(1)$ & $0.01(2)$ & 1 \\
\cline { 2 - 5 } & V-Oc & $2.00(5)$ & $0.003(9)$ & 2 \\
\cline { 2 - 5 } & V-Oc & 1.8264 & $0.003(9)$ & 1 \\
\cline { 2 - 5 } & V-Ov & 2.9007 & 0.001 & 1 \\
\cline { 2 - 5 } & V-V & $3.11(4)$ & $0.009(5)$ & 2 \\
\cline { 2 - 5 } & V-V & 3.454 & $0.02(2)$ & 3 \\
\hline
\end{tabular}


Table 4: $\mathrm{V}$ local structure from EXAFS data for $\mathrm{AIVO}_{4}$-like samples.

\begin{tabular}{|c|c|c|c|c|}
\hline Catalyst & Shell & $r(\AA)$ & $s^{2}\left(\AA^{-2}\right)$ & $\mathrm{N}$ \\
\hline \multirow{4}{*}{$\mathrm{AlVO}_{4}$} & $\mathrm{~V}-\mathrm{O}(11)$ & 1.7125 & $0.012(1)$ & 4 \\
\hline & $\mathrm{V}-\mathrm{O}(3)$ & 3.0085 & $0.001(9)$ & 0.67 \\
\hline & $\mathrm{V}-\mathrm{O}(10)$ & 3.1500 & $0.01(1)$ & 0.67 \\
\hline & V-AI(3) & 3.1896 & $0.02(1)$ & 3.33 \\
\hline & & & & \\
\hline \multirow{3}{*}{ V10Al } & $\mathrm{V}-\mathrm{O}(11)$ & $\frac{1.78(1)}{29(1)}$ & $\frac{0.031(3)}{0.001}$ & $\frac{4}{067}$ \\
\hline & $\begin{array}{c}V-U(3) \\
V-O(10)\end{array}$ & 3.15000 & $0.0(1)$ & 0.61 \\
\hline & V-Al(3) & 3.4186 & $0.03(2)$ & 3.33 \\
\hline & & & & \\
\hline \multirow{3}{*}{ V10Si } & $\mathrm{V}-\mathrm{O}(11)$ & $1.56(2)$ & 0.002 & 1 \\
\hline & $\mathrm{V}-\mathrm{O}(6)$ & $1.84(4)$ & $0.027(6)$ & 4 \\
\hline & $\mathrm{V}-\mathrm{O}(3)$ & $3.0(1)$ & $0.01(2)$ & 1 \\
\hline
\end{tabular}


Table 5: Schematic summary of some literature reports on the nature and role of active sites for the ODH of propane.

\begin{tabular}{|c|c|}
\hline Reference & Hypothesis \\
\hline 7 & $\begin{array}{l}\text { One-electron reduction pathway for isolated vanadyls; two-electrons path } \\
\text { for dimeric species }\end{array}$ \\
\hline 6 & Two-electrons reduction pathway not excluded for monomeric species \\
\hline 8 & Preferential two-electron reduction pathway \\
\hline 10 & $\begin{array}{l}\text { One-electron pathway active for alumina-supported samples, two- } \\
\text { electrons one for silica-based ones }\end{array}$ \\
\hline 11 & $\begin{array}{l}\text { One-electron reduction way for both silica and alumina-supported } \\
\text { samples }\end{array}$ \\
\hline 8, here & $\begin{array}{l}\text { Polymerisation degree } \mathrm{SiO}_{2}<<\mathrm{ZrO}_{2}<\mathrm{Al}_{2} \mathrm{O}_{3} \text {; isolated species detected } \\
\text { only over silica. }\end{array}$ \\
\hline $38,40-42$ & Description of the umbrella-type configuration of the active sites. \\
\hline Here & $\begin{array}{l}\text { Higher dispersion (isolated vanadyls) obtained with flame pyrolysis, } \\
\text { particularly over silica; for the latter support increasing dispersion led to } \\
\text { lower Brønsted acidity and higher average V oxidation state }\end{array}$ \\
\hline $14-16$ & $\begin{array}{l}\text { Lower } \mathrm{V}=\mathrm{O} \text { bond length (higher bond strength) for silica-supported } \\
\text { samples than for alumina-based ones }\end{array}$ \\
\hline $14-16,21-23$ & $\begin{array}{l}\text { V polymerisation increases reaction rate up to monolayer; low selectivity } \\
\text { for bulk } \mathrm{V}_{2} \mathrm{O}_{5}\end{array}$ \\
\hline 44 & $\mathrm{~V}=\mathrm{O}$ bond active for $\mathrm{H}$ abstraction, $\mathrm{V}-\mathrm{O}-\mathrm{V}$ for water formation \\
\hline 45 & $\mathrm{~V}=\mathrm{O}$ active for total oxidation; $\mathrm{V}-\mathrm{O}-\mathrm{V}$ for selective propene formation \\
\hline 46 & Higher selectivity for tetrahedral or octahedral V sites \\
\hline 13-16, here & Correlation of $\mathrm{V}=\mathrm{O}$ strength/length with activity and selectivity to propene \\
\hline 47 & $\begin{array}{l}\text { No influence of } \mathrm{V}=\mathrm{O} \text { strength/length with activity and selectivity to } \\
\text { propene }\end{array}$ \\
\hline 48 & $\mathrm{~V}=\mathrm{O}$ involved in the consecutive oxidation of propene \\
\hline Here & $\begin{array}{l}\text { Increasing dispersion increases selectivity, particularly under anaerobic } \\
\text { conditions; for the } \mathrm{VO}_{x} / \mathrm{SiO}_{2} \text { catalysts the increase of selectivity has been } \\
\text { also correlated to decreasing Brønsted acidity and higher average } \mathrm{V} \\
\text { oxidation state }\end{array}$ \\
\hline
\end{tabular}




\section{FIGURE CAPTIONS}

Fig. 1: SEM analysis of samples V10Si (a), V50Si (b), V10Al (c), V50Al (d). Marker size = $300 \mathrm{~nm}$ except for $\mathrm{a})=100 \mathrm{~nm}$.

Fig. 2: TEM analysis: V10Si (a), V28Si (b), V50Si (c,d), V50AI (e).

Fig. 3: TEM-EDX maps of $\mathrm{V}$ and Si for sample $\mathrm{V} 10 \mathrm{Si}$ (a) and $\mathrm{V10Al}$ (b). Marker size: 20 and $50 \mathrm{~nm}$, respectively.

Fig. 4: XPS spectra in the $O_{1 s} B E$ range (a) and in the $V_{2 p} B E$ range (b). XPS curves were stacked for clarity.

Fig. 5: XANES spectra (a) and the corresponding derivatives (b).

Fig. 6: EXAFS data fitting for the reference $\mathrm{V}_{2} \mathrm{O}_{5}$ (a) and $\mathrm{V} 50 \mathrm{Al}(\mathrm{b})$.

Fig. 7: Tentative picture of $\mathrm{V}$-sites in $\mathrm{V}_{2} \mathrm{O}_{5}$-like $(\mathrm{a}, \mathrm{b}, \mathrm{c})$ and $\mathrm{AlVO}_{4}$-like $(\mathrm{d}, \mathrm{e})$ samples. When relevant, numerical labels refer to increasingly distant oxygen species.

Fig. 8: FT-IR spectra recorded after dosing ca. 0.4 mbar on ${\mathrm{V} / \mathrm{SiO}_{2}}_{2}$ samples outgassed at $150^{\circ} \mathrm{C}$. Difference spectra are reported, as obtained after subtraction of spectra of bare samples.

Fig. 9: Correlation between the position of the band due to the bending vibration of $\mathrm{NH}_{4}{ }^{+}$ species (as measured in Fig. 9) and the red-shift of the $\mathrm{O}-\mathrm{H}$ stretching mode $(\Delta \mathrm{v})$, as previously measured after $\mathrm{CO}$ adsorption at nominal $-196^{\circ} \mathrm{C}^{14}$.

Fig. 10: $\mathrm{FT}$-IR spectra recorded after dosing ca. 0.4 mbar of ammonia on $\mathrm{V} / \mathrm{Al}_{2} \mathrm{O}_{3}$ samples outgassed at $150^{\circ} \mathrm{C}$. Difference spectra are reported, as obtained after subtraction of spectra of bare samples.

Fig. 11: (a) Propane conversion rate at $400^{\circ} \mathrm{C}\left(425^{\circ} \mathrm{C}\right.$ for samples V10Si-i and V10Al-i) and $525^{\circ} \mathrm{C}\left(550^{\circ} \mathrm{C}\right.$ for samples V10Si and VAG1) normalised per gram of V; (b) Propylene productivity at $400^{\circ} \mathrm{C}\left(425^{\circ} \mathrm{C}\right.$ for samples V10Si-i and V10Al-i) and $525^{\circ} \mathrm{C}\left(550^{\circ} \mathrm{C}\right.$ for samples V10Si and VAG1) normalised per mass of V. 
Fig. 12: Propane conversion rate (a) and propylene productivity (b) under redox conditions. Reaction temperature $550^{\circ} \mathrm{C}$; data collected on the fully oxidised sample.

Fig. 13: Possible structure of acid sites in V10Si and V10Al samples.

Fig. 14: Correlation between $V$ site-isolation, acid strength and selectivity to propene under anaerobic reaction conditions at $550^{\circ} \mathrm{C}$. Data collected at $12 \pm 1 \%$ conversion.

Fig. 15: Maximum selectivity to propene (\%), measured under anaerobic reaction conditions at $550^{\circ} \mathrm{C}$, at $12 \pm 1 \%$ conversion, reported as a function of the average $\mathrm{BE}$ of the $V_{2 p ~ 3 / 2}$ peak $(e V)$ reported in Table 2. 
Fig. 1: SEM analysis of samples V10Si (a), V50Si (b), V10Al (c), V50Al (d). Marker size = $300 \mathrm{~nm}$ except for $\mathrm{a})=100 \mathrm{~nm}$.

(a)

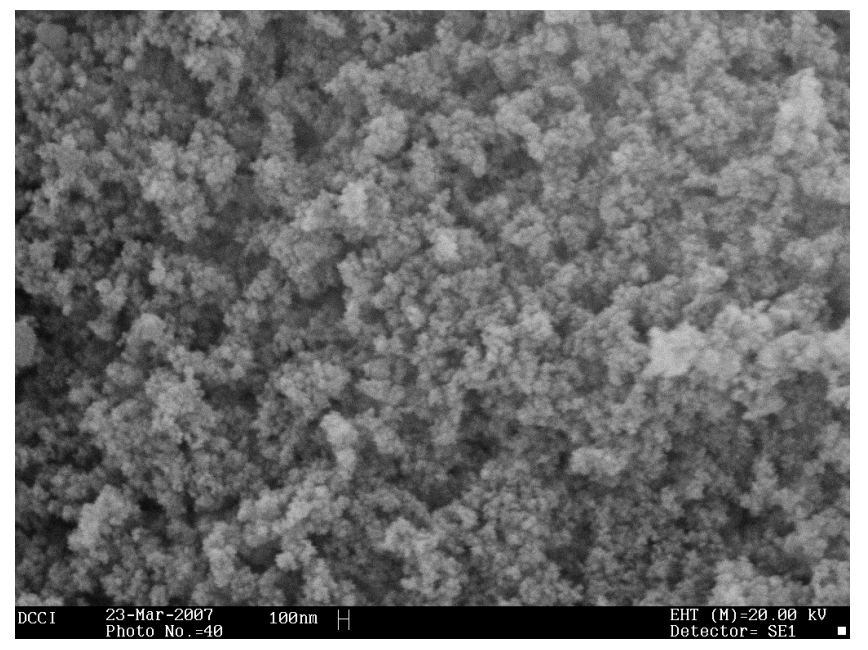

(b)

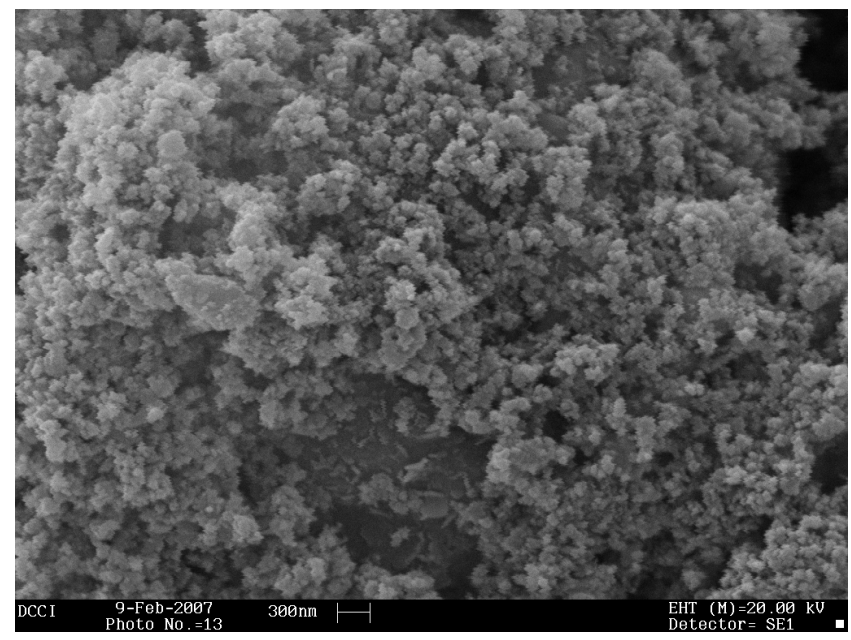




\section{Page 35 of 53}

(c)

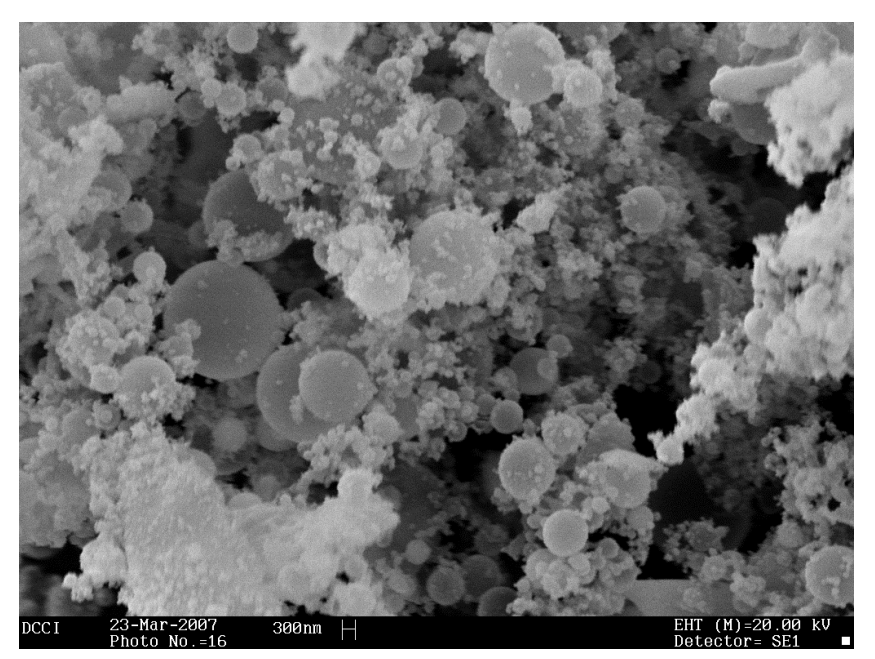

(d)

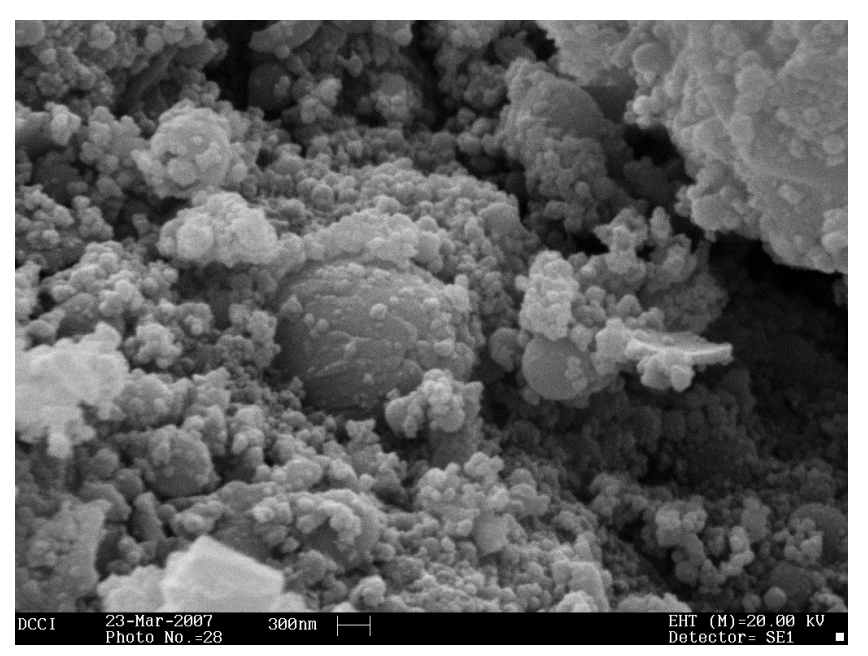


Fig. 2: TEM analysis: V10Si (a), V28Si (b), V50Si (c,d), V50Al (e).

(a)

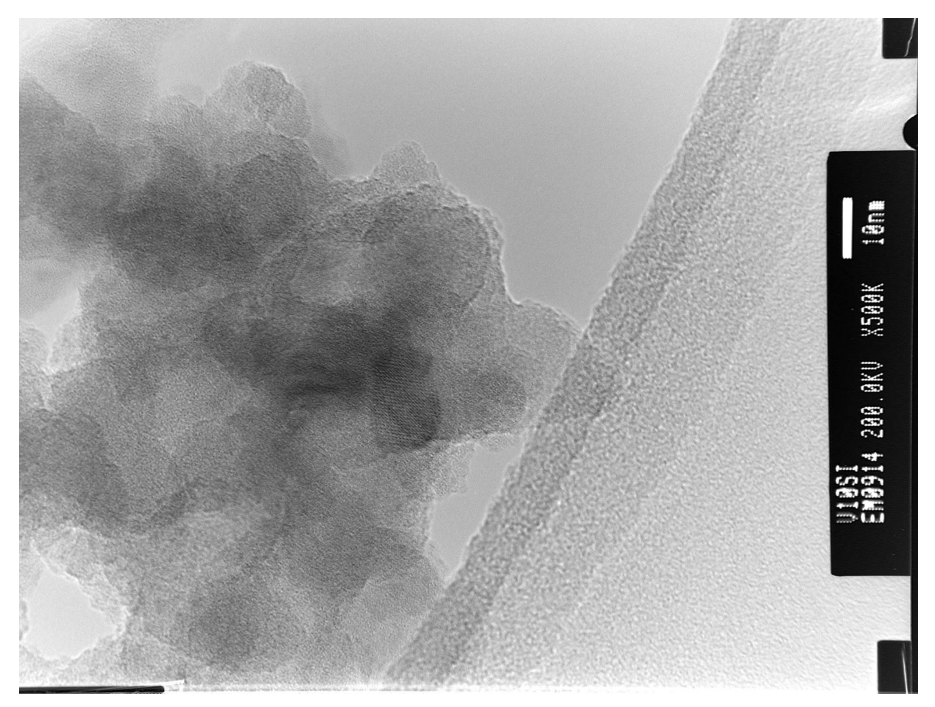

(b)

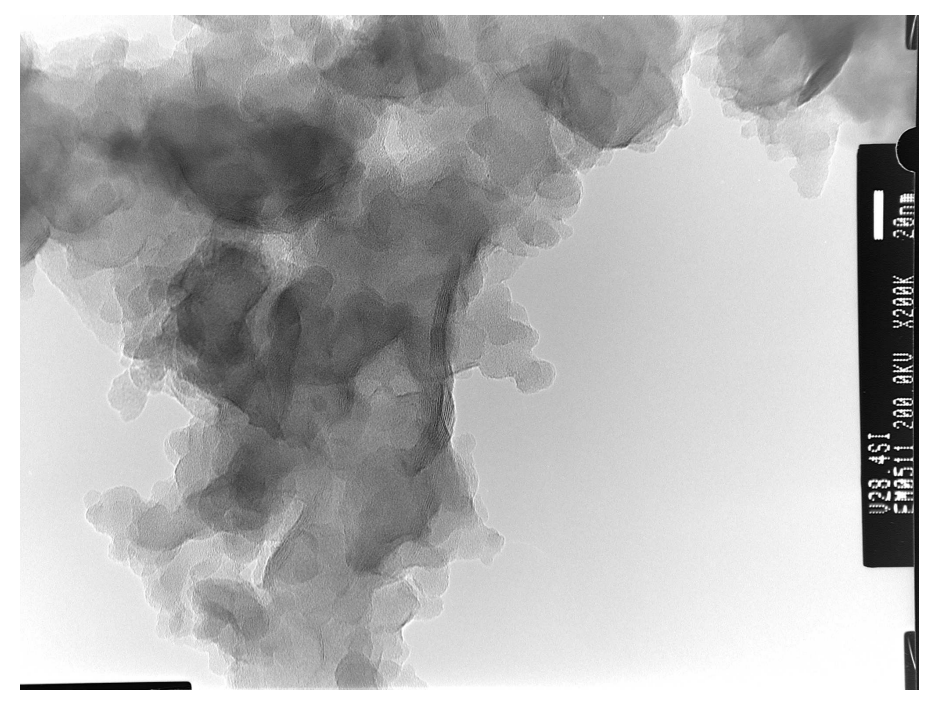


(c)

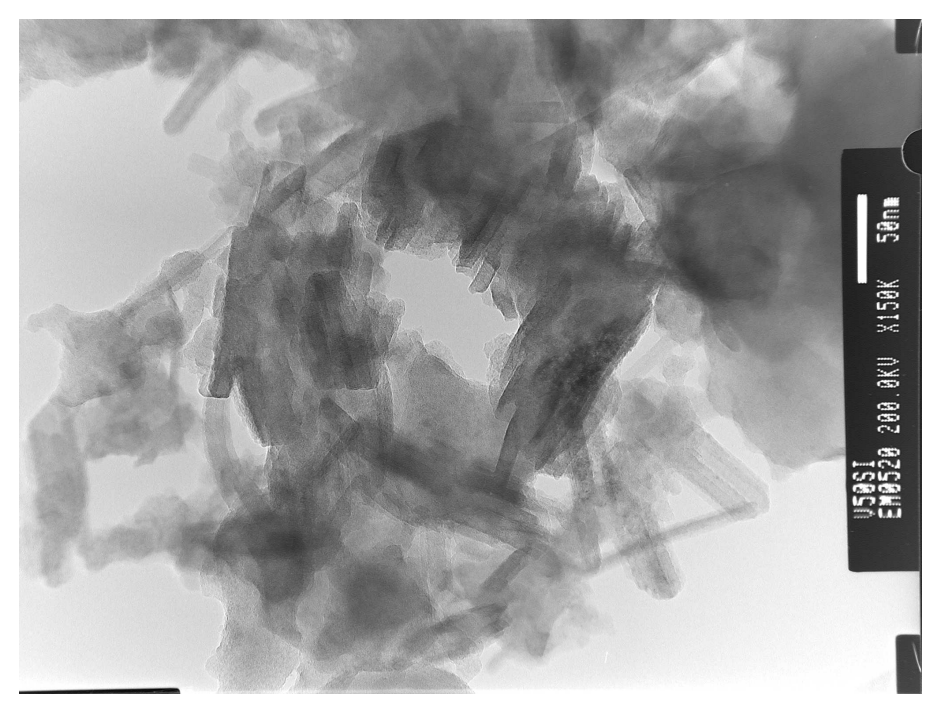

(d)

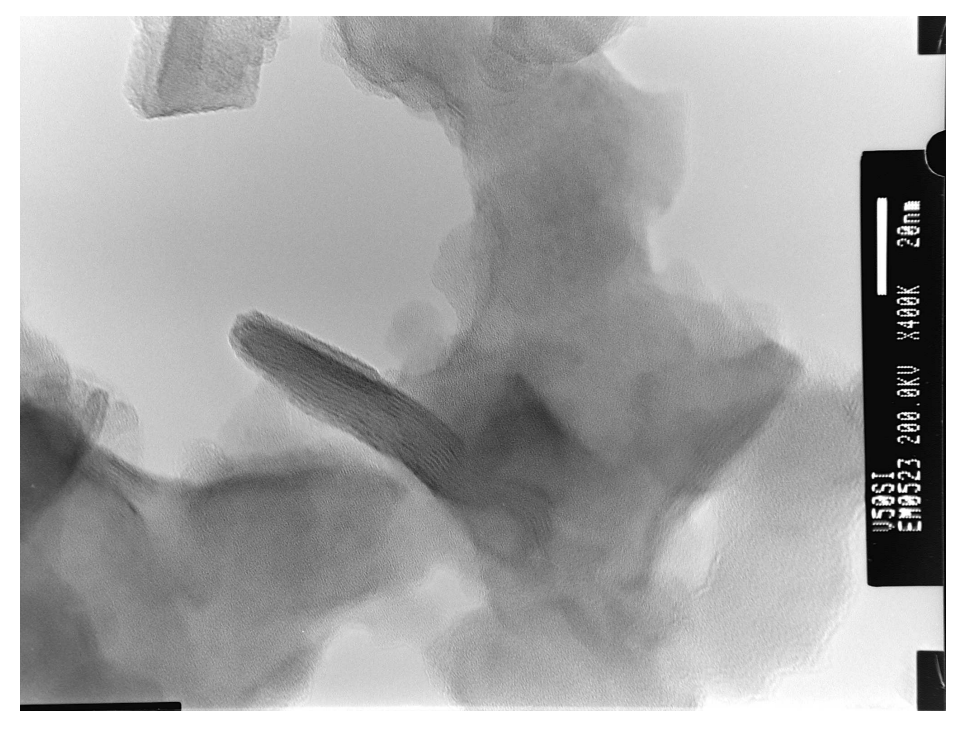


(e)

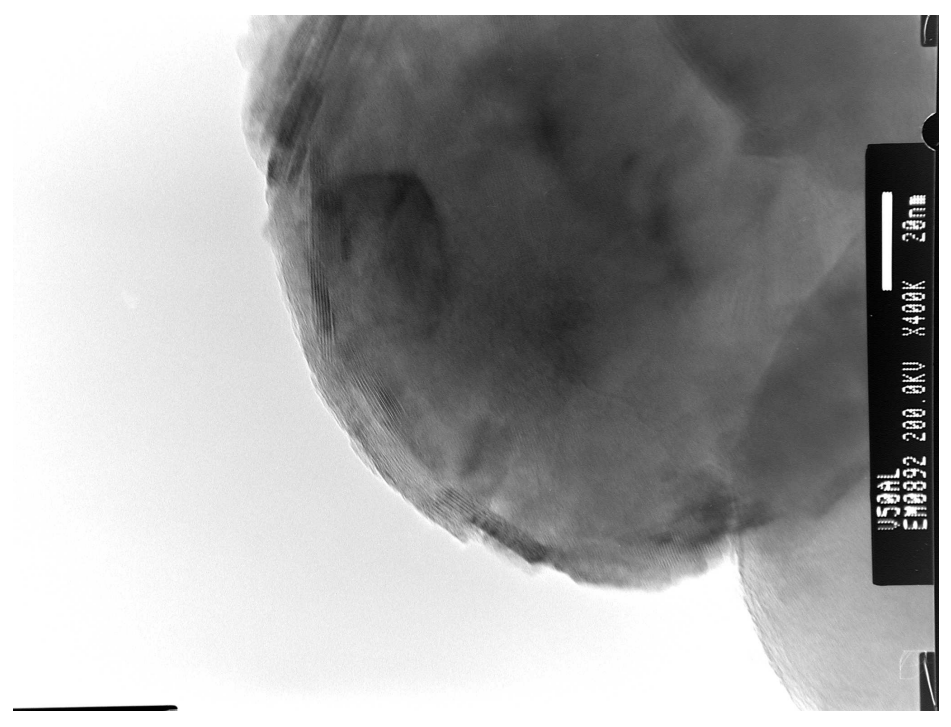

Fig. 3: TEM-EDX maps of $\mathrm{V}$ and Si for sample V10Si (a) and V10Al (b). Marker size: 20 and $50 \mathrm{~nm}$, respectively.

(a)

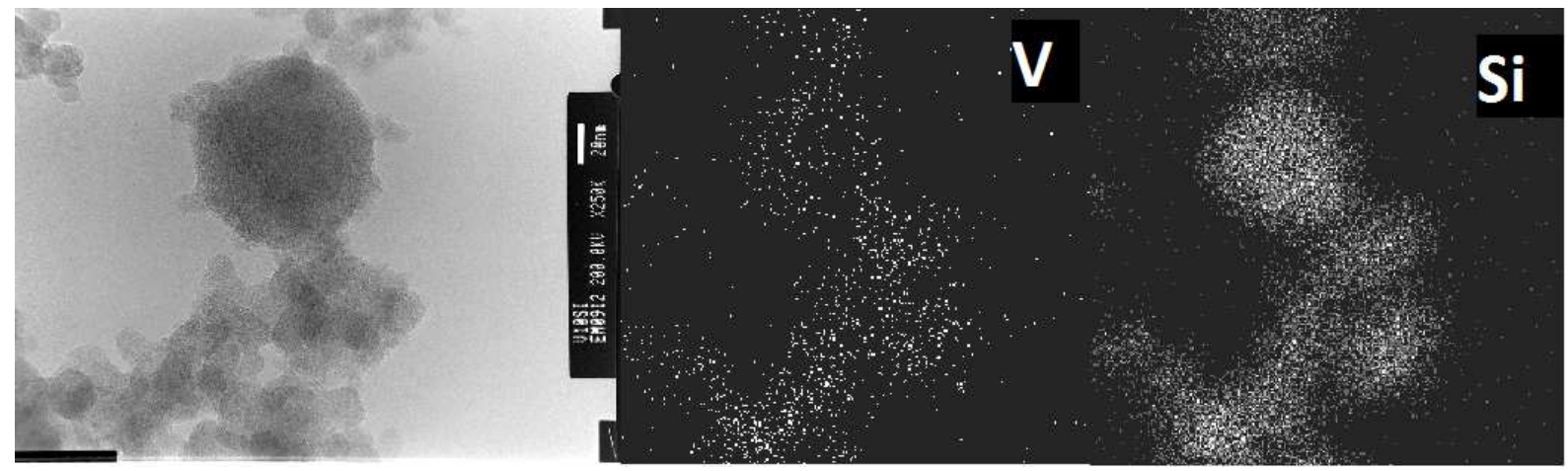


(b)

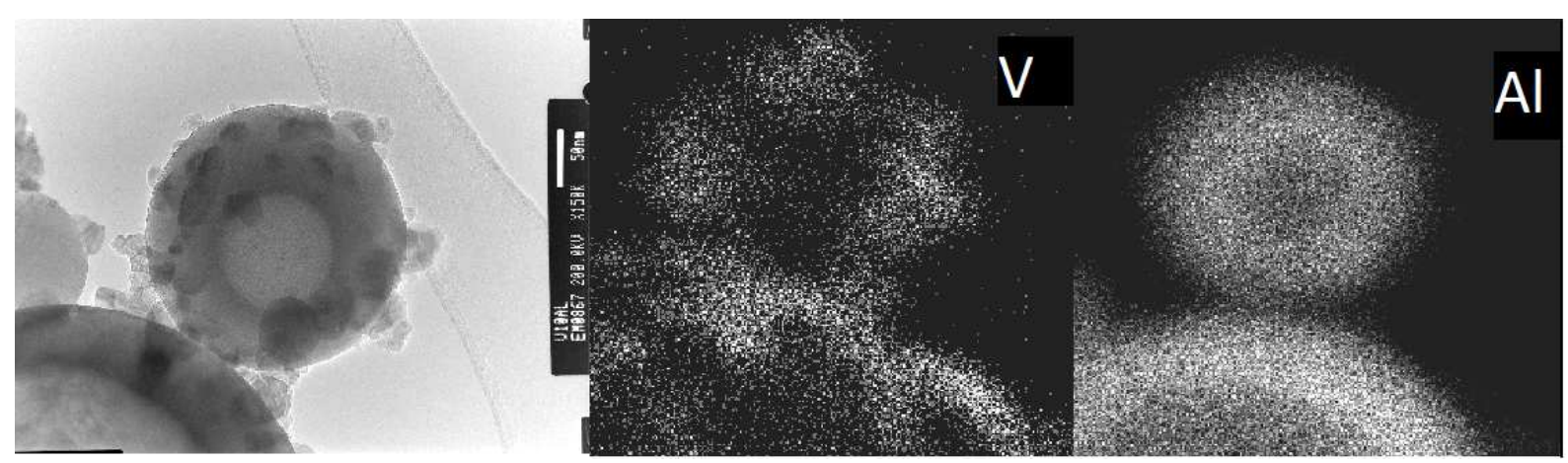

Fig. 4: XPS spectra in the $\mathrm{O}_{1 \mathrm{~s}} B E$ range (a) and in the $V_{2 p} B E$ range (b). XPS curves were stacked for clarity.
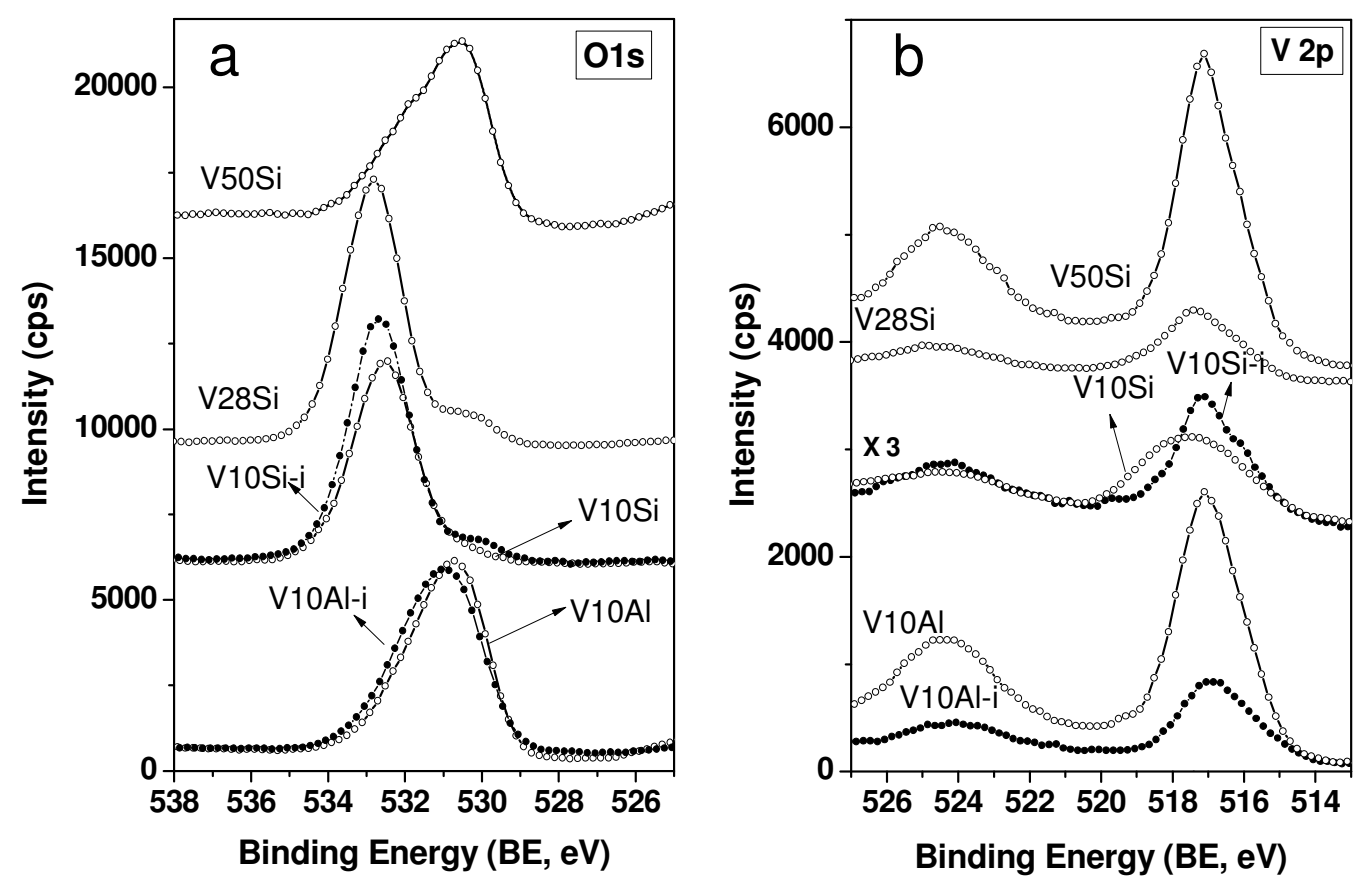
Fig. 5: XANES spectra (a) and the corresponding derivatives (b).

Fig. 5a

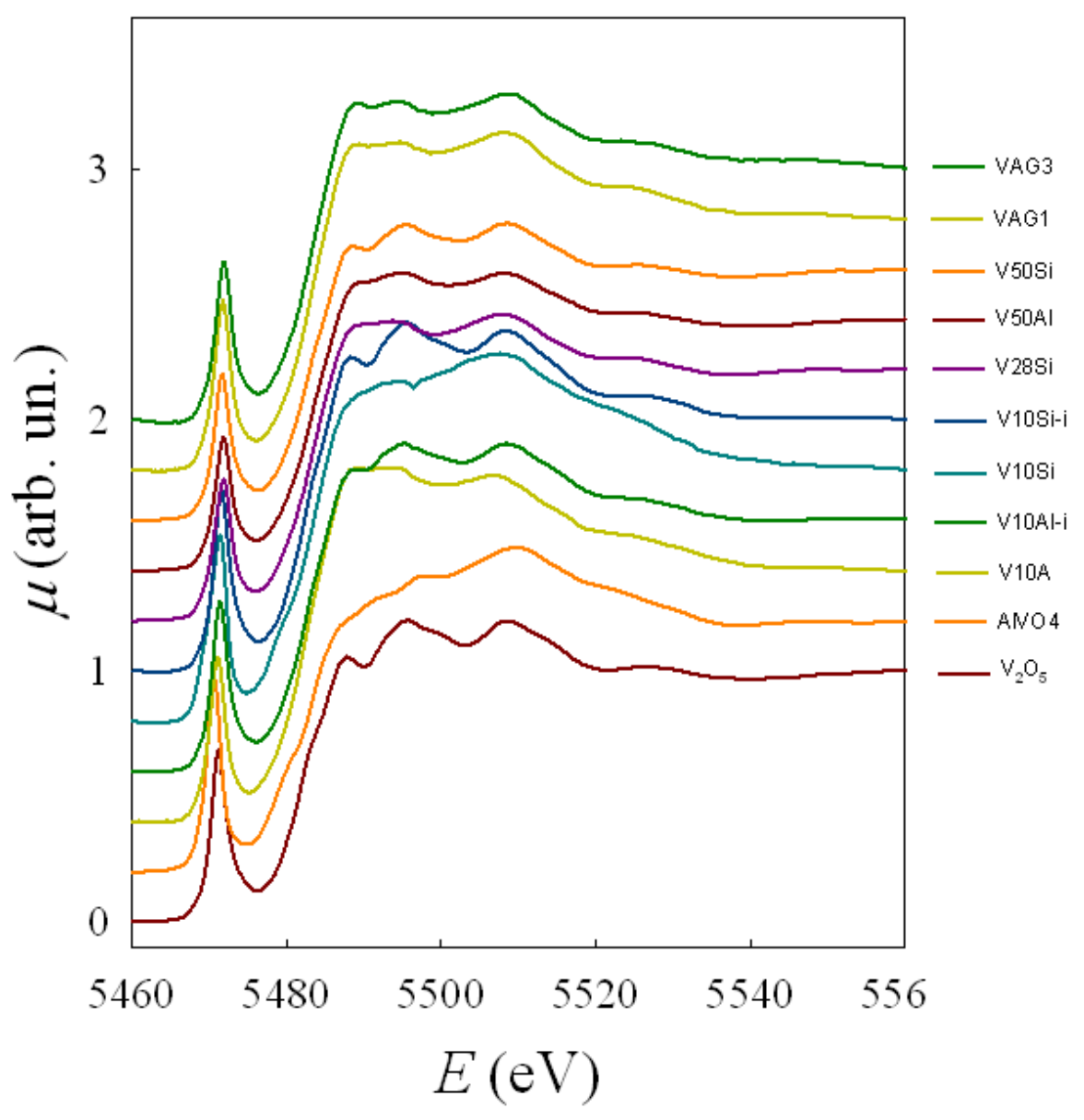


Fig. 5b

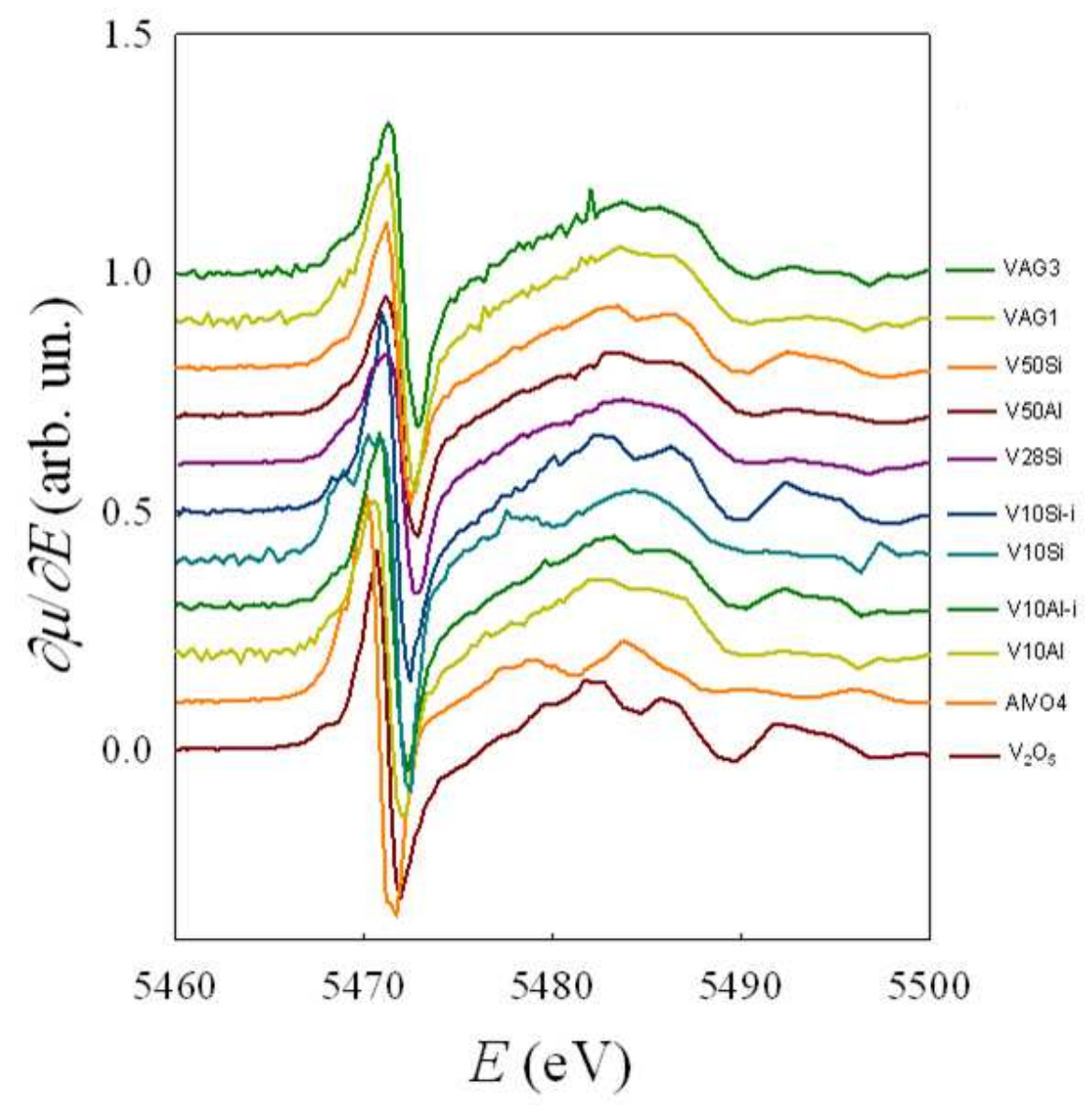


Fig. 6: EXAFS data fitting and the corresponding Fourier Transform for the reference $\mathrm{V}_{2} \mathrm{O}_{5}$ (a) and V50Al (b).

(a)
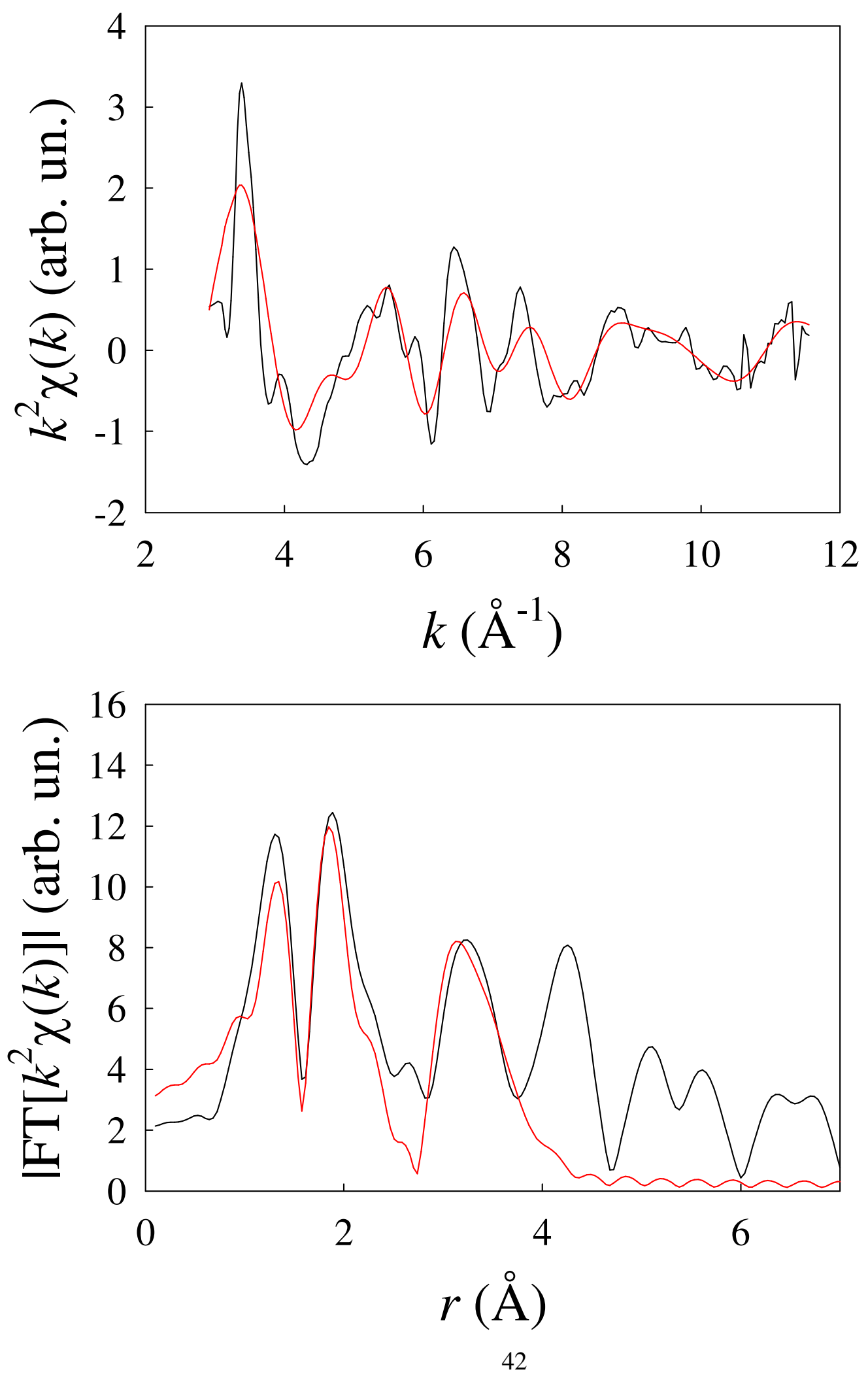

ACS Paragon Plus Environment 
(b)
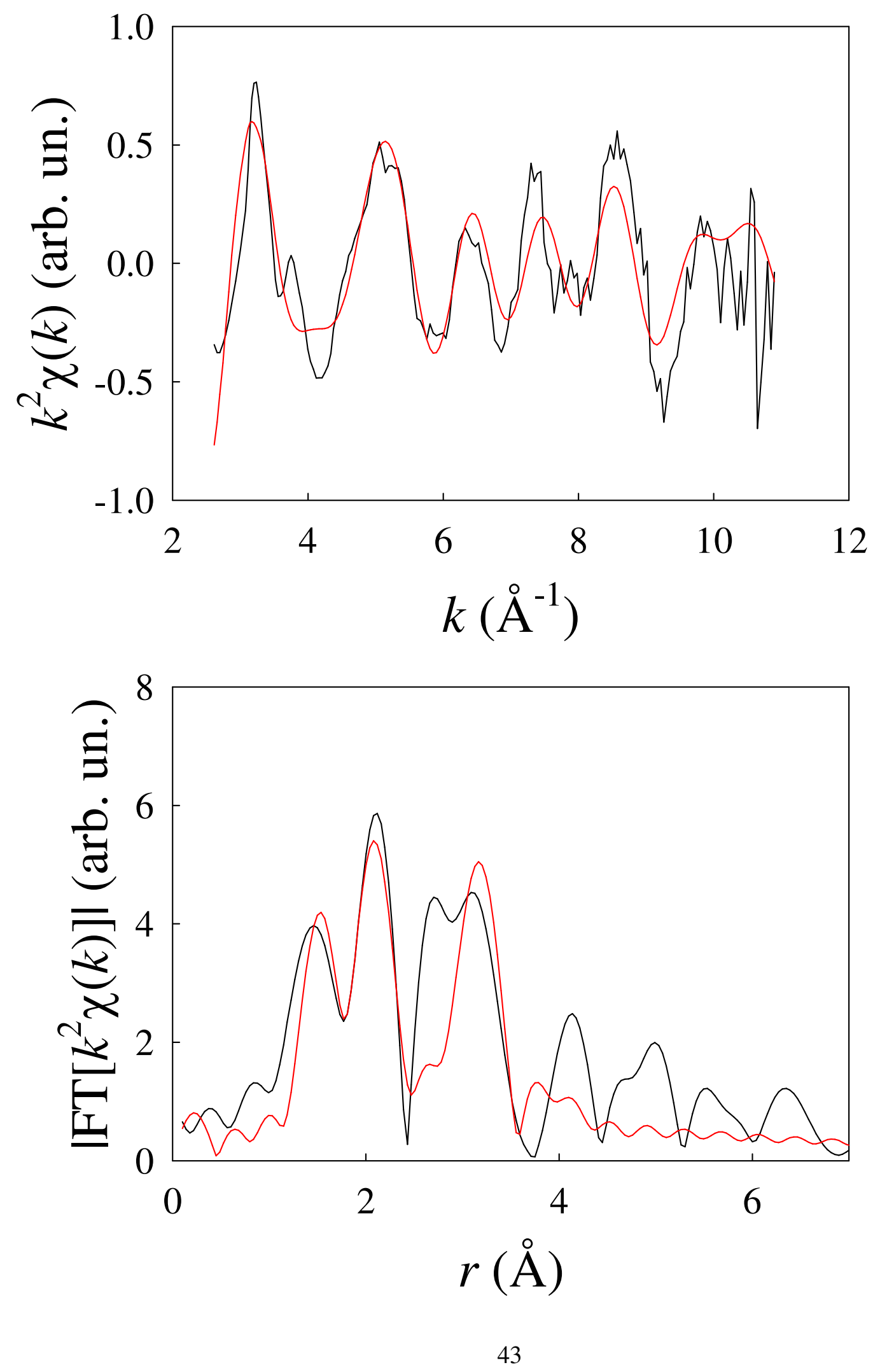

ACS Paragon Plus Environment 
Fig. 7: Tentative picture of $\mathrm{V}$-sites in $\mathrm{V}_{2} \mathrm{O}_{5}$-like $(\mathrm{a}, \mathrm{b}, \mathrm{c})$ and $\mathrm{AlVO}_{4}$-like $(\mathrm{d}, \mathrm{e})$ samples. When relevant, numerical labels refer to increasingly distant oxygen species.
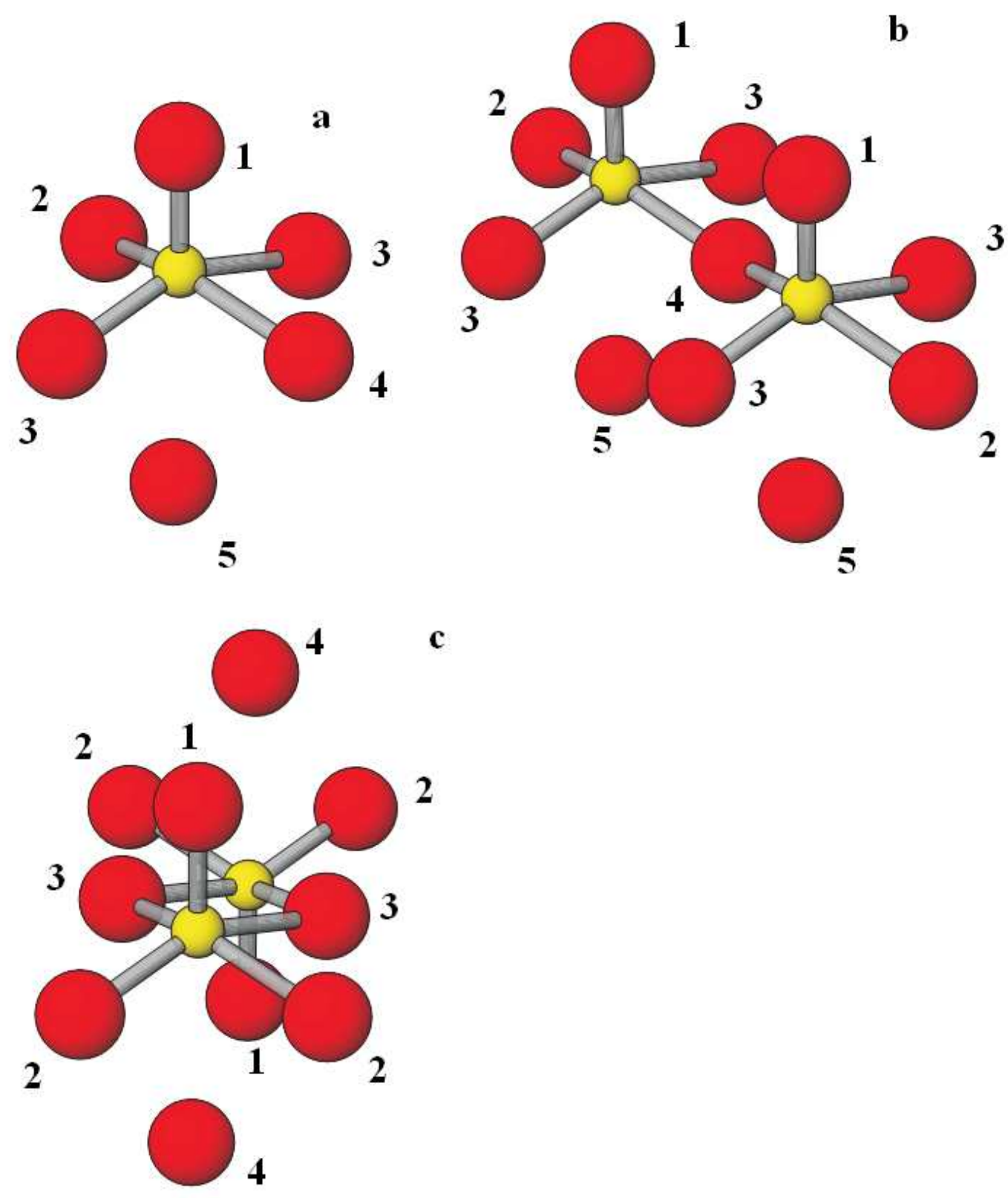


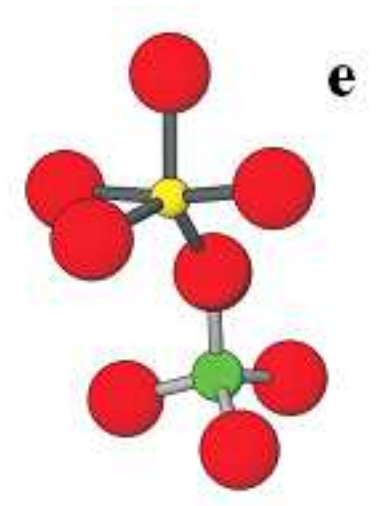

Fig. 8: FT-IR spectra recorded after dosing ca. 0.4 mbar on $\mathrm{V} / \mathrm{SiO}_{2}$ samples outgassed at $150^{\circ} \mathrm{C}$. Difference spectra are reported, as obtained after subtraction of spectra of bare samples.

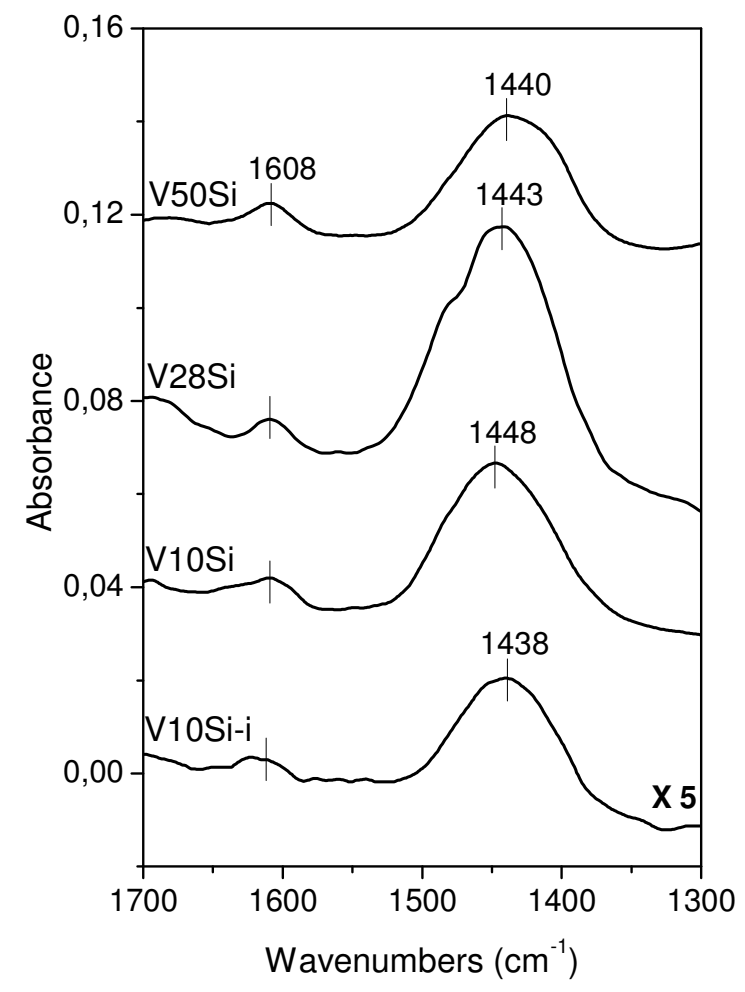


Fig. 9: Correlation between the position of the band due to the bending vibration of $\mathrm{NH}_{4}{ }^{+}$species (as measured in Fig. 9) and the red-shift of the O-H stretching mode $(\Delta v)$, as previously measured after $\mathrm{CO}$ adsorption at nominal $-196^{\circ} \mathrm{C}{ }^{14}$.

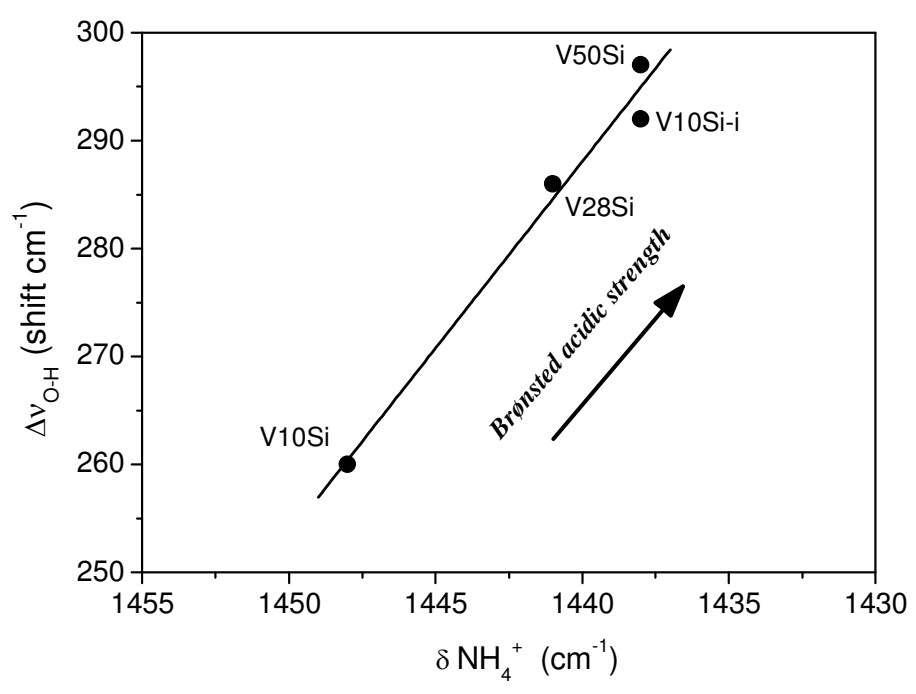

46

ACS Paragon Plus Environment 
Fig. 10: FT-IR spectra recorded after dosing ca. 0.4 mbar of ammonia on $\mathrm{V} / \mathrm{Al}_{2} \mathrm{O}_{3}$ samples outgassed at $150^{\circ} \mathrm{C}$. Difference spectra are reported, as obtained after subtraction of spectra of bare samples.

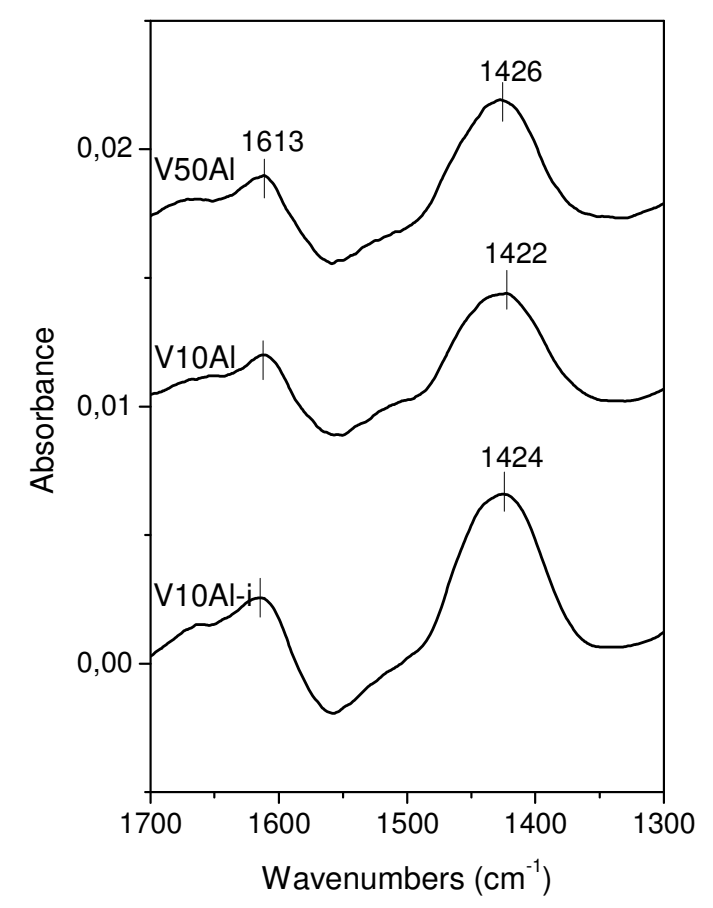


Fig. 11: (a) Propane conversion rate at $400^{\circ} \mathrm{C}\left(425^{\circ} \mathrm{C}\right.$ for samples V10Si-i and V10Al-i) and $525^{\circ} \mathrm{C}\left(550^{\circ} \mathrm{C}\right.$ for samples V10Si and VAG1) normalised per gram of V; (b) Propylene productivity at $400^{\circ} \mathrm{C}\left(425^{\circ} \mathrm{C}\right.$ for samples V10Si-i and V10Al-i) and $525^{\circ} \mathrm{C}\left(550^{\circ} \mathrm{C}\right.$ for samples V10Si and VAG1) normalised per mass of V. Data collected under aerobic conditions.

(a)

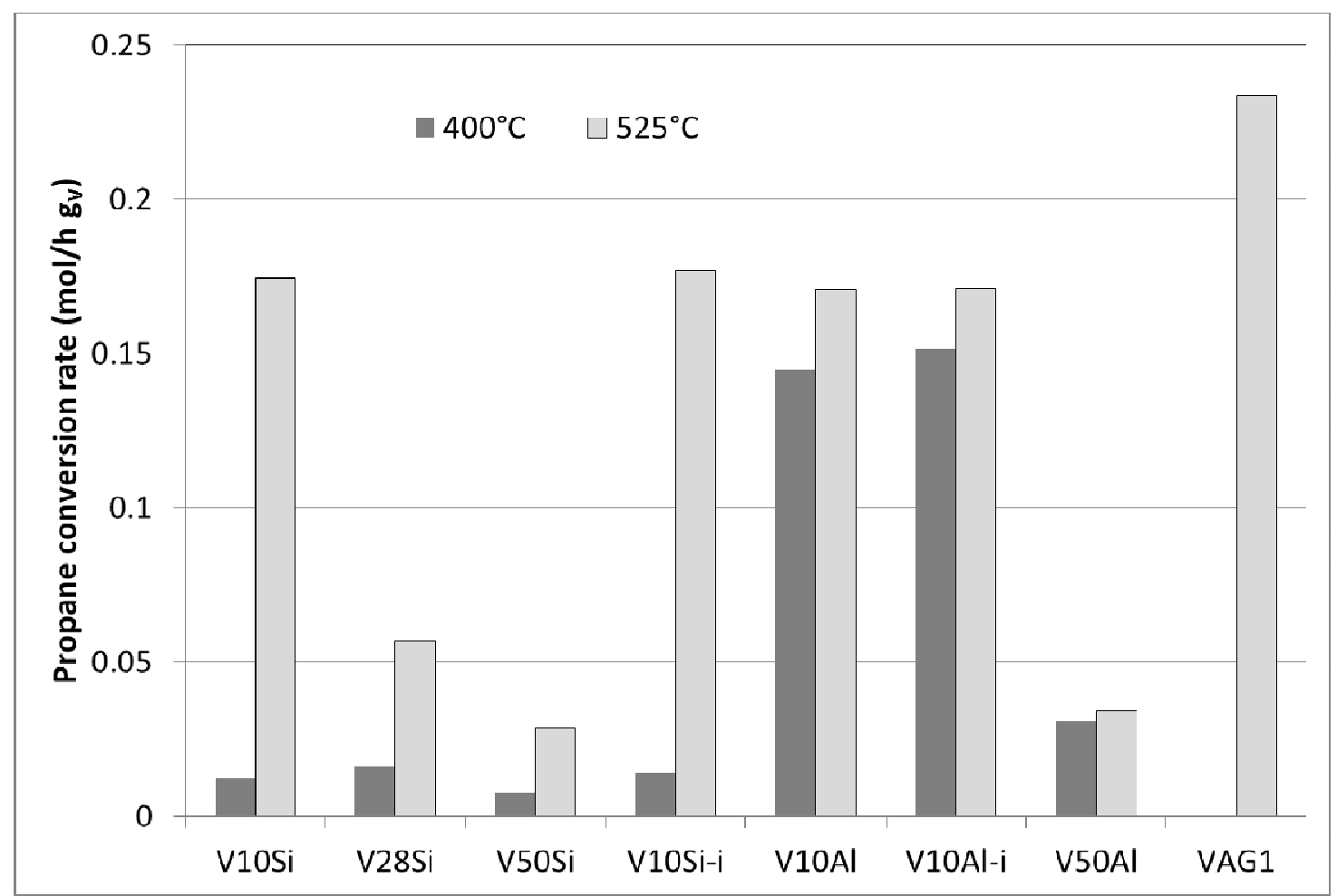


(b)

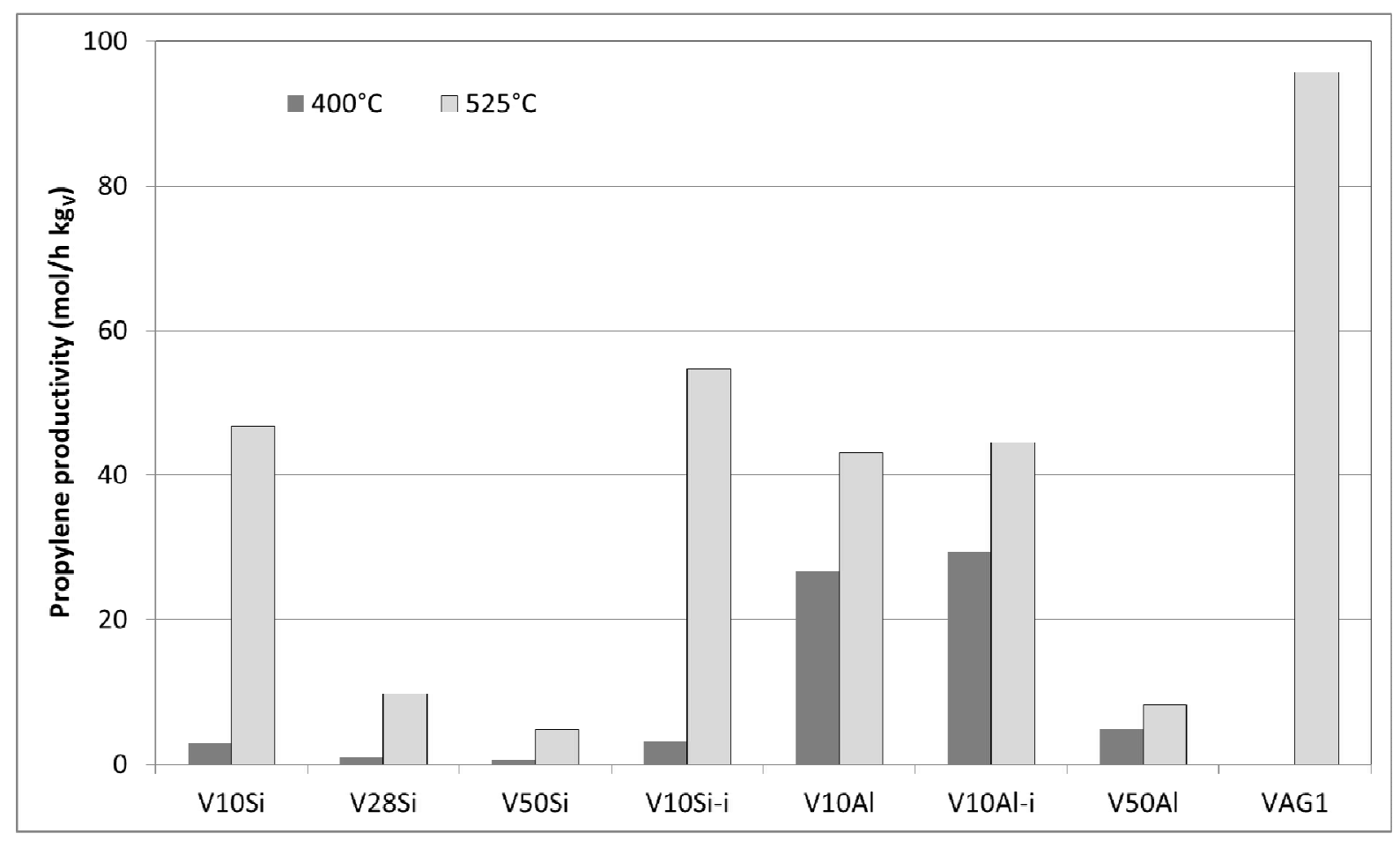

1

2

3

4

5

6

8

9

10

11

12

13

14

15

16

17

18

19

20

21

22

23

24

25

26

27

28

29

30

31

32

33

34

35

36

37

38

39

40

41

42

43

44

45

46

47

48

49

50

51

52

53

54

55

56

57

58

59

60
49

ACS Paragon Plus Environment 
Fig. 12: Propane conversion rate (a) and propylene productivity (b) under anaerobic conditions. Reaction temperature $550^{\circ} \mathrm{C}$; data collected on the fully oxidised sample.

(a)

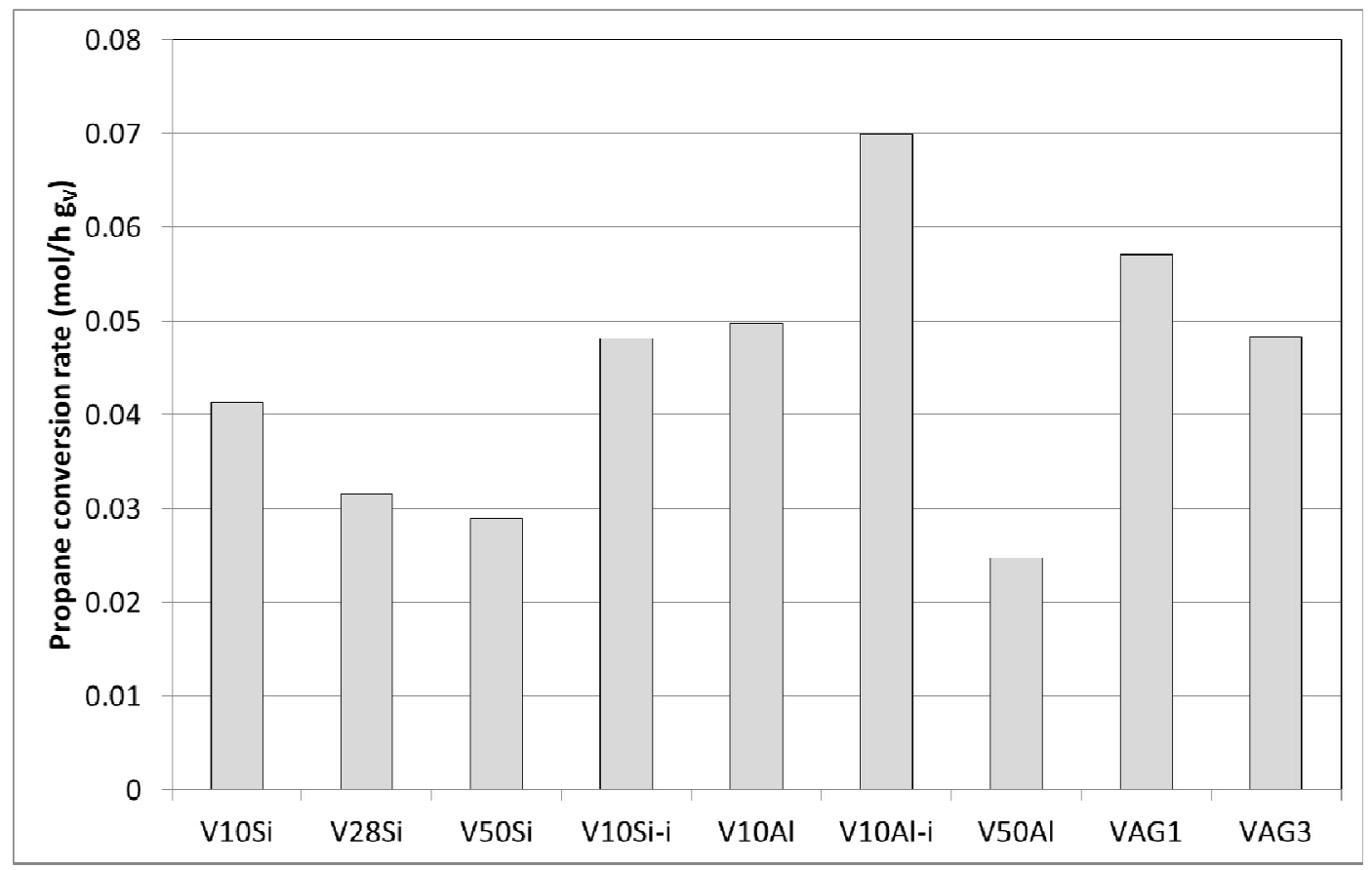

(b)

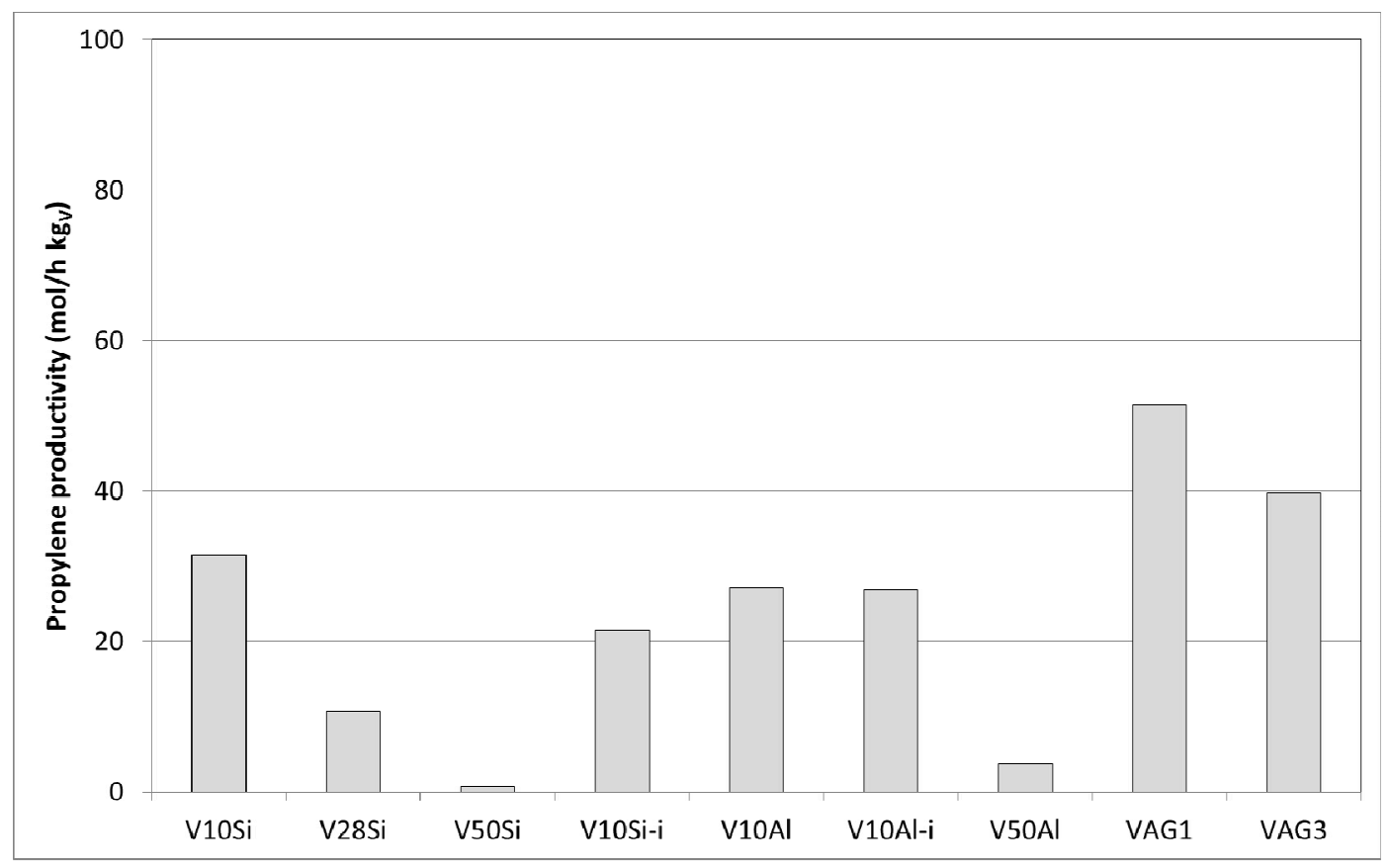


Fig. 13: Possible structure of acid sites in V10Si and V10Al samples.

1

2

3

4

5

6

7

8

9

10

11

12

13

14

15

16

17

18

19

20

21

22

23

24

25

26

27

28

29

30

31

32

33

34

35

36

37

38

39

40

41

42

43

44

45

46

47

48

49

50

51

52

53

54

55

56

57

58

59

60

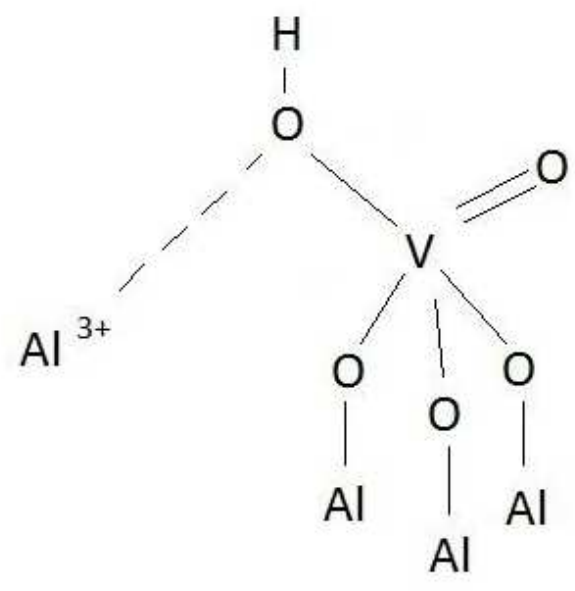

Fig. 14: Correlation between $\mathrm{V}$ site-isolation, acid strength and selectivity to under anaerobic reaction conditions at $12 \pm 1 \%$ iso-conversion (reaction temperature $550^{\circ} \mathrm{C}$ ).

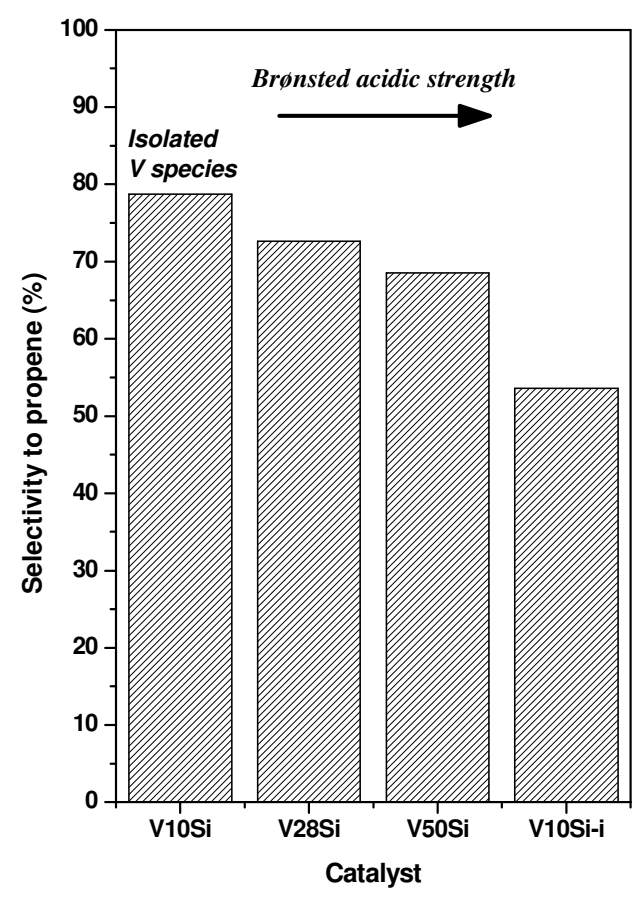


Fig. 15: Black squares: values of selectivity to propene (\%), measured under anaerobic reaction conditions at $550^{\circ} \mathrm{C}$ and at $12 \pm 1 \%$ iso-conversion, reported as a function of the average $B E$ of the $V_{2 p ~ 3 / 2}$ peak $(e V)$ reported in Table 2. White circles: values of initial selectivity to propene $(\%)$ measured after 1 min-on-stream $\left({ }^{*}\right)$ with V10Si and V10Si-i samples.

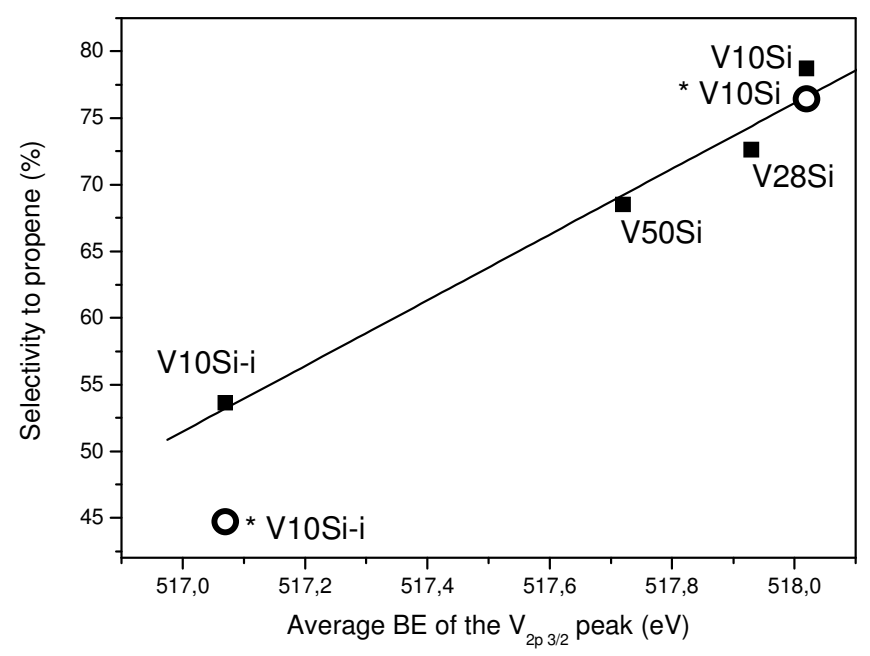

52 


\section{TABLE OF CONTENTS}

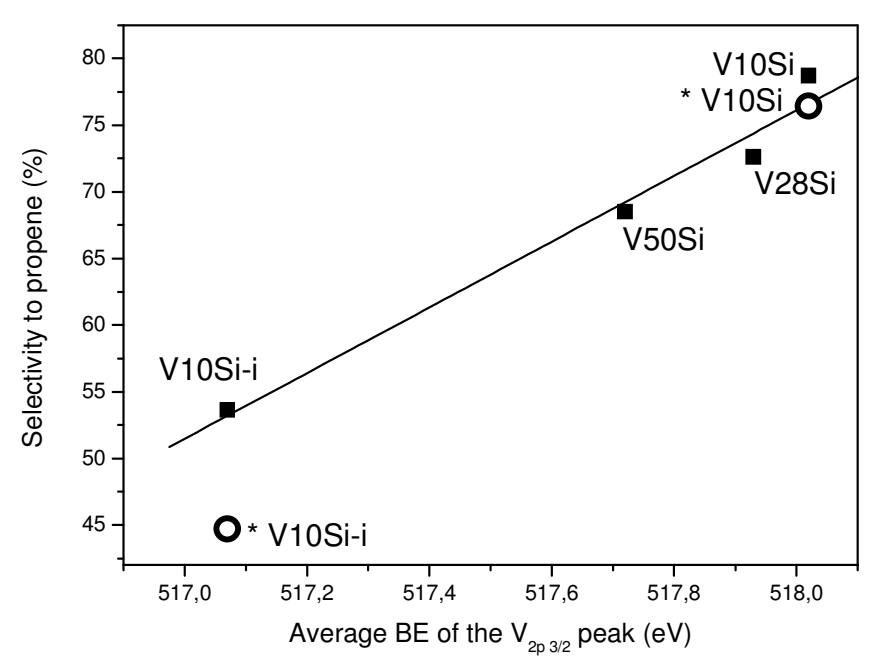

1

2

5

6

7

8

10

11

12

14

15

16

17

18

19

20

21

22

23

24

25

26

27

28

29

30

31

32

33

34

35

36

37

38

39

40

41

42

43

44

45

46

47

48

49

50

51

52

53

54

55

56

57

58

59

60 